NBER WORKING PAPER SERIES

MONETARY POLICY, BOUNDED RATIONALITY, AND INCOMPLETE MARKETS

\author{
Emmanuel Farhi \\ Iván Werning \\ Working Paper 23281 \\ http://www.nber.org/papers/w23281 \\ NATIONAL BUREAU OF ECONOMIC RESEARCH \\ 1050 Massachusetts Avenue \\ Cambridge, MA 02138 \\ March 2017
}

We are grateful to Mikel Petri, who provided outstanding research assistance. For useful comments we thank Xavier Gabaix, Jordi Gali, Mark Gertler, Luigi Iovino, Benoit Mojon, Martin Schneider, Andrei Shleifer, Gianluca Violante, Mirko Wiederholt, and Michael Woodford. We also thank participants at the NYU/Banque de France/PSE conference on Monetary Policy in Models with Heterogeneous Agents, the NBER Behavioral Macroeconomics Summer Institute, and the ECB Annual Research Conference. The views expressed herein are those of the authors and do not necessarily reflect the views of the National Bureau of Economic Research.

NBER working papers are circulated for discussion and comment purposes. They have not been peerreviewed or been subject to the review by the NBER Board of Directors that accompanies official NBER publications.

(C) 2017 by Emmanuel Farhi and Iván Werning. All rights reserved. Short sections of text, not to exceed two paragraphs, may be quoted without explicit permission provided that full credit, including $\odot$ notice, is given to the source. 
Monetary Policy, Bounded Rationality, and Incomplete Markets

Emmanuel Farhi and Iván Werning

NBER Working Paper No. 23281

March 2017, Revised February 2019

JEL No. E03,E1,E4,E52

\begin{abstract}
$\underline{\text { ABSTRACT }}$
This paper extends the benchmark New-Keynesian model by introducing two frictions: (1) agent heterogeneity with incomplete markets, uninsurable idiosyncratic risk, and occasionally binding borrowing constraints; and (2) bounded rationality in the form of level-k thinking. Compared to the benchmark model, we show that the interaction of these two frictions leads to a powerful mitigation of the effects of monetary policy, which is more pronounced at long horizons, and offers a potential rationalization of the "forward guidance puzzle". Each of these frictions, in isolation, would lead to no or much smaller departures from the benchmark model.
\end{abstract}

Emmanuel Farhi

Harvard University

Department of Economics

Littauer Center

Cambridge, MA 02138

and NBER

emmanuel.farhi@gmail.com

Iván Werning

Department of Economics, E52-536

MIT

50 Memorial Drive

Cambridge, MA 02142

and NBER

iwerning@mit.edu 


\title{
Monetary Policy, Bounded Rationality, and Incomplete Markets*
}

\author{
Emmanuel Farhi \\ Harvard University \\ Iván Werning \\ MIT
}

September 2017

This paper extends the benchmark New-Keynesian model with a representative agent and rational expectations by introducing two key frictions: (1) agent heterogeneity with incomplete markets, uninsurable idiosyncratic risk, and occasionally-binding borrowing constraints; and (2) bounded rationality in the form of level- $k$ thinking. Compared to the benchmark model, we show that the interaction of these two frictions leads to a powerful mitigation of the effects of monetary policy, which is much more pronounced at long horizons, and offers a potential rationalization of the "forward guidance puzzle". Each of these frictions, in isolation, would lead to no or much smaller departures from the benchmark model. We conclude that the interaction of bounded rationality and market frictions improves the ability of the model to account for the effects of monetary policy.

\section{Introduction}

The baseline New Keynesian setup is a workhorse model for monetary policy analysis. However, in its basic form, it also has implications that are controversial or unrealistic. For example, despite various concrete results that limit the number of equilibria, indeterminacy concerns remain. In addition, although the model provides a rationale for effective monetary policy, some view the power of monetary policy as too effective, and changes in future interest rates may be especially powerful—the so-called "forward guid-

${ }^{*}$ We are grateful to Mikel Petri, who provided outstanding research assistance. For useful comments we thank Xavier Gabaix, Jordi Gali, Mark Gertler, Luigi Iovino, Benoit Mojon, Martin Schneider, Andrei Shleifer, Gianluca Violante, Mirko Wiederholt, and Michael Woodford. We also thank participants at the NYU/Banque de France/PSE conference on Monetary Policy in Models with Heterogeneous Agents, the NBER Behavioral Macroeconomics Summer Institute, and the ECB Annual Research Conference. 
ance puzzle" ${ }^{1}$ Finally, while the model can explain recessive effects arising at the zero lower bound or following from other contractive monetary policies, these effects seem excessive. ${ }^{2}$ These shortcomings provide important reasons to entertain departures from the basic New Keynesian setup.

In our view, the extreme forward-looking nature of the model due to complete markets and rational expectations underlies these frustrating properties. This paper studies the effects of monetary policy in the presence of nominal rigidities exploring two realistic departures from standard benchmark models. First, we depart from the representative agent or complete market assumption by considering, instead, heterogeneous agents and financial market imperfections, including both incomplete insurance and borrowing constraints. Second, we depart from rational expectations, by adopting a particular form of bounded rationality. As we will show, these two frictions interact in powerful ways and help make the model more realistic by fixing its aforementioned shortcomings.

We study monetary policy and focus on changes in current and future interest rates and study their effect on aggregate output. In standard New-Keynesian models changes in future real interest rates are equally potent to changes in current real interest rates, a property that some have labeled the "forward guidance puzzle", as introduced by . 3 Although each of the two departures we consider from the benchmark model may affect this property, we show that each deviation in isolation exerts only a moderate influence. The combined effect of both deviations, however, is potent and potentially affects the workings of monetary policy significantly, reducing the sensitivity of current output to future interest rate changes-we call this the mitigation effect-the more so, the further in the future they take place-we call this the horizon effect. In other words, incomplete markets and level- $k$ bounded rationality are complements. This highlights a more general point, that it is not always enough to investigate one deviation at a time from standard

\footnotetext{
${ }^{1} \mathrm{~A}$ similar issue arises in the context of the fiscal policy: as shown by Christiano, Eichenbaum and Rebelo (2011) at the zero lower bound spending is very stimulative. As shown by Farhi and Werning (2016a), future spending is more powerful—a "fiscal forward guidance puzzle". In ongoing work we apply the framework we introduce here to fiscal policy and show that level- $k$ thinking mitigates the inflation-output feedback loop which is responsible for these effects, and improves the realism of the model.

${ }^{2}$ For example, in deterministic models, recessionary forces become arbitrarily large as the duration of the liquidity trap lengthens, and in some stochastic models, when the probability of remaining in the liquidity trap is large enough, the equilibrium simply ceases to exist. These effects are exact manifestations of the forward guidance puzzle in reverse-applied to a situation where monetary policy is too contractionary over the horizon of the liquidity trap. Although we de not develop these applications explicitly in the paper, our resolution of the forward guidance puzzle also leads to a resolution of these liquidity trap paradoxes.

${ }^{3}$ Given standard empirical identification challenges, which are only heightened when focusing on forward guidance shocks, relative to standard monetary shocks, one can interpret the term 'puzzle' as reflecting the property of standard models relative to a prior where monetary policy in the far future has smaller effects on current activity.
} 
benchmark models.

Our first deviation drops the representative agent and complete market assumptions. Our model is populated by heterogenous agents making consumption decisions subject to idiosyncratic shocks to income that cannot be insured. In addition, borrowing may also be limited. These frictions affect the capacity of households to smooth their consumption, potentially affecting the potency of forward guidance. Intuitively, if agents expect to be borrowing constrained in the near future, then changes in future interest rates should not greatly influence their current consumption decisions. This line of reasoning was put forth by McKay et al. (2016). However, as shown by Werning (2015), while incomplete markets always have an effect on the level of aggregate consumption, the way it affects its sensitivity to current and future interest rates is less clear. Indeed, this sensitivity is completely unchanged in some benchmark cases and may be enhanced in others. This implies that the power of forward guidance is not necessarily diminished by incomplete markets, at least not without adopting other auxiliary assumptions. ${ }^{4}$ Here we adopt the benchmark cases that imply the neutral conclusion that incomplete markets have no effect on the sensitivity of aggregate consumption to interest rates.

Our second deviation drops the rational-expectations assumption, adopting instead a form of bounded rational expectations closely related to the notions of "calculation equilibrium" and of "reflective equilibrium" introduced in macroeconomic settings by Evans and Ramey (1992; 1995; 1998) and García-Schmidt and Woodford (2015) respectively. They are based on a finite discrete deductive procedure involving $k$ iterations, which we refer to as "level-k thinking", which describes how, starting from a status quo rational-expectations equilibrium, agents form expectations about changes in future macroeconomic variables in response to a given change in policy. As we shall argue, our choice amongst the "wilderness" of options of non-rational expectations seems well suited to the economic and policy scenario that we shall focus on.

In our case, the change in policy is the announcement of a new interest rate path, (or, more generally, a new path for the interest rate policy rule). ${ }^{5}$ Households are perfectly aware of the entire new path of current and future interest rates set by the monetary au-

\footnotetext{
${ }^{4}$ As highlighted in Werning (2015), two features that push to mitigate the impact of future interest rates relative to current interest rates on current aggregate consumption are: (i) procyclicality of income risk, making precautionary savings motives low during a recession; and (ii) countercyclicality of liquidity relative to income, making asset prices or lending fluctuate less than output. If one adopts the reverse assumptions, as a large literature does-so that recessions heighten risk, precautionary savings and are accompanied by large drops in asset prices or lending relative to GDP-then aggregate consumption becomes even more sensitive to future interest rates, relative to current interest rates.

${ }^{5}$ To simplify our model and allow for a non-linearized solution we consider cases where there is no ongoing aggregate uncertainty; all uncertainty has been resolved at $t=0$, including any unexpected "MIT" shock. Thus, rational expectations is equivalent to perfect foresight.
} 
thority and, as a result, the entire yield curve immediately adjusts to reflect this announcement. ${ }^{6}$ We are motivated by specific policy contexts, especially at the zero lower bound, where the intended interest rate path is directly and exhaustively communicated by the central bank; economic actors pay close attention to these announcements. In contrast, expectations for other endogenous macroeconomic variables, such as output or inflation, are not under the direct control of the central bank nor directly announced and, thus, agents can only form beliefs about them indirectly. In our formulation, agents make an effort to think through the behavior of these variables, but stop short of achieving perfect foresight. This is motivated by two other considerations. First, the notion that the status quo is a natural focal point to start to reason through the effects of the policy on future variables and that agents may be limited, or believe that others are limited, in performing this deduction. Second, we are interested in relatively unfamiliar scenarios, with interest rates near zero at an effective lower bound, where learning protocols that converge to rational expectations cannot be naturally invoked. Indeed, agents may recognize the that past experience may be a poor guide in such relatively unfamiliar scenarios. For these reasons, backward-looking learning approaches to the formation of expectations may be inadequate. Our modeling of expectations is entirely forward-looking and deductive.

The simplest interpretation of our basic setting assumes that prices and wages are fully rigid. This allows us to follow McKay et al. (2016) by focusing on changes in the real interest rate path on consumption, since real and nominal interest rates changes obviously coincide when inflation is unresponsive. ${ }^{7}$ However, even when prices are sticky but not fully rigid, monetary policy changes affect the real interest rate path. ${ }^{8}$ We maintain this full price rigidity assumption in Sections 2-5 and relax it in Section 6 where we consider sticky but not fully rigid prices.

In our model, households care to forecast the path for aggregate income because of its effect on future household income. With full price rigidity, given the new interest rate

\footnotetext{
${ }^{6}$ This is an important difference with Gabaix (2017) who assumes that agents are inattentive to the interest rate and with Angeletos and Lian (2017) who assume that agents only observe the interest rate with some noise. As a result, in these models, the yield curve is "stale" and only partially adjusts to shocks and policy announcement. We see this as an important advantage of our model in light of the recent experience in which the yield curve has been reactive to shocks and policy announcements.

${ }^{7}$ Standard New Keynesian models with a purely forward looking Phillips curve with levels of nominal rigidities calibrated to frequency of price changes between 6-12 months may imply large and counterfactual changes in inflation to shocks, especially at the zero lower bound. A line of work attempts to modify the basic models to explain the why inflation appears to have been relatively well anchored during the Great Recession.

${ }^{8}$ When monetary policy is described by nominal interest rate changes, then one must also consider the effect of inflation, which exerts an endogenous effect on the real interest rate path. Even in this case, understanding the effects of real interest rate is instrumental and remains relevant since consumption depends on the expected real interest rate path.
} 
path, this turns out to be the only endogenous macroeconomic variable that households need to forecast. They form these expectations according to the iterative level-k iterative which we describe next.

Level-1 thinking assumes that agents expect the path for future output to remain as in the original rational-expectations equilibrium before the announced change in the path of interest rates. Given current assets and income, individuals choose consumption and savings, reacting to the new interest rate path, using the status quo expectations for future aggregate income. In equilibrium, aggregate output equals aggregate consumption in each period, and the economy is in (general) equilibrium. In the $k$-th deductive round, households take the path of future output to be the equilibrium path of output that obtains in the previous round, etc. This process converges to the rational-expectations equilibrium when the number of rounds $k$ goes to $\infty$.

An interesting advantage of working with level- $k$ is that it sidesteps issues of indeterminacy, as argued forcefully by García-Schmidt and Woodford (2015). Indeed, for any shift in the path of interest rates, the equilibrium outcome for any level $k$ is unique. Indeed, one can see level- $k$ thinking as a selection device which isolates a particular rational expectations equilibrium in the limit when $k$ goes to $\infty$, without having to resort to policy rules or the Taylor principle. ${ }^{9}$

We start in Section 2 by defining our different equilibrium concepts (temporary equilibrium, rational-expectations equilibrium, level- $k$ equilibrium) in a reduced form model for which the key primitive is a reduced-form aggregate consumption function. We also offer a decomposition of the response of output to interest rate changes under rational expectations into a partial equilibrium effect and a general equilibrium effect. The partial equilibrium effect computes the change in aggregate consumption resulting from the change in the path of interest rates, holding the expected path for aggregate income unchanged. The general equilibrium effect then considers the change in aggregate consumption resulting from adjusting the expectations of future aggregate income. Under some conditions, the level- 1 outcome coincides with the partial equilibrium response, since it keeps expectations about future aggregate income unchanged. As one increases the number of rounds of thinking, the level- $k$ outcome incorporates to a greater extent the general equilibrium effects from increased future expected aggregate income, converging to the rational-expectations outcome as $k$ goes to $\infty$.

In the subsequent sections, we spell out explicit models of individual optimizing be-

\footnotetext{
${ }^{9}$ When prices are rigid, level- $k$ converges to rational expectations when $k$ goes to $\infty$. When prices have some degree of flexibility, each level- $k$ equilibrium remains uniquely determined, but the convergence depends on the monetary policy rule. We obtain convergence with a Taylor rule.
} 
havior and map their implications into the reduced-form aggregate consumption function. We can then apply the equilibrium definitions of Section 2.

We start with the complete-markets, or equivalently, the representative-agent case, in Section 3. As we show, bounded rationality affects the response of consumption to the path of interest rates. First, the effect of the current interest rate is equal to the one under rational expectation, but the effects of any future interest rate change on output are lower, implying that there is a mitigation effect. Second, this mitigation is stronger for interest rate changes occurring further out in the future, implying that there is a horizon effect.

Qualitative conclusions aside, our calculations show that the mitigation and horizon effects obtained with level-k bounded rationality and a representative agent are relatively modest. In particular, for level-1 we show that the response of current output to an interest rate change decreases exponentially with the horizon with an exponent equal to the interest rate. That is, the response is proportional to $e^{-r \tau}$ where $\tau$ is the horizon and $r$ is the interest rate. For example, with an interest rate of $2 \%$, the effect on output of an interest rate change in 4 years is a fraction 0.92 of the effect of a contemporaneous interest rate change, arguably a small amount of mitigation and horizon.

Sections 4 and 5 turn to economies with incomplete markets. We wish to separate two different aspects of market incompleteness: the presence of binding borrowing constraints and uninsurable idiosyncratic income risk. To isolate the impact of occasionallybinding borrowing constraints, we consider first in Section 4 a perpetual youth overlapping generations model. On the one hand, the presence of annuities eliminates uninsurable idiosyncratic income risk, removing precautionary saving motives. On the other hand, as is well known, the death rate in overlapping generation models can be reinterpreted as frequently binding borrowing constraints. This shortens the effective planning horizon and increases the marginal propensity to consume.

We specify the perpetual youth model with logarithmic utility to ensure that there are neither mitigation nor horizon effects under rational expectations. Intuitively, although binding borrowing constraints mitigate the substitution effect from changes in interest rates, it enhances the reaction of consumption to changes in income, i.e. increases marginal propensities to consume (MPCs). This larger income effect exactly offsets the smaller substitution effect for our baseline specification. The general point is that under rational expectations incomplete markets does not necessarily deliver a departure in the aggregate response of consumption to the path of interest rates, even though the underlying mechanism and intuition may be quite different.

Turning to level-k bounded rationality we obtain mitigation and horizon effects, but these effects are now amplified relative to those in the representative agent case. In par- 
ticular, for level-1 the response of current output to an interest rate change decreases exponentially with the horizon at a rate equal to the interest rate, $r$, plus the rate of death, $\lambda$, which should be interpreted as the frequency of binding borrowing constraints. That is, the response is proportional to $e^{-(r+\lambda) \tau}$. For example, a frequency of binding borrowing constraints of $15 \%$ implies a response of current output to an interest rate change 4 years into the future of almost half of the effect of a contemporaneous interest rate change.

Section 5 considers a standard Bewley-Aiyagari-Huggett model. This model combines occasionally-binding borrowing constraints and precautionary savings due to uninsurable idiosyncratic uncertainty. We allow for a long-lived outside asset in fixed supply-commonly referred to as a "Lucas tree" - that determines the amount of liquidity in the economy. Again, we specify the model to ensure that there are no mitigation or horizon effects under rational expectations. Indeed, the aggregate properties of the model are identical to those of a representative-agent. This provides a neutral platform to investigate the interaction of bounded rationality and incomplete markets.

As is well known, Bewley-Aiygari-Huggett models are not analytically tractable, so we must turn to numerical simulations. Our explorations show that this model delivers significant mitigation and horizon effects. Consistent with our earlier results, we find that these effects are especially strong when the model is parameterized to feature significant risk and binding borrowing constraints.

In our baseline we consider a steady state with a $2 \%$ annual interest rate and use a fairly standard idiosyncratic income process. We set the fraction of outside liquidity to output at 1.44 (as in McKay et al. 2016). ${ }^{10}$ The implied fraction of borrowing-constrained agents in the steady state is then $14.7 \%$. Quantitatively, in our baseline calibration, we find that the effect on output of an interest rate change in 4 years is about half of the effect of a contemporaneous interest rate change; this number is similar to our perpetual youth example. Calibrations with a lower amount of liquidity yield a higher fraction of borrowing-constrained agents and give greater mitigation and horizon effects.

Overall, these exercises show the interaction of bounded rationality and incomplete markets has the potential for significant mitigation and horizon effects in monetary policy, even if each element has only modest effects in isolation.

Finally, in Section 6, we study the role of inflation by departing from the assumption of fully rigid prices. Household must now also form expectations regarding future inflation. We modify the model of Section 5 to incorporate monopolistic competition and staggered time-dependent pricing a la Calvo, as well as explicit labor supply and labor demand

\footnotetext{
${ }^{10}$ This value for the fraction of outside liquidity to output $\frac{V}{Y}=1.44$ is meant to capture the value of liquid (as opposed to illiquid) wealth in the data.
} 
decisions. Once again, we explore this model numerically, fully nonlinearly, without the use of log-linearization techniques.

Because inflation is responsive, the "forward guidance puzzle" under rational expectations is enhanced. Indeed, this baseline now features anti-horizon effects in the sense that the response of current output and inflation increase with the horizon of monetary policy. These anti-horizon effects arise because of a feedback loop between output and inflation: higher outputgenerates higher inflation, which reduces real interest rates and further increases output, etc. The longer the horizon of the monetary policy change, the longer the time horizon over which this feedback loop plays out, and the stronger its effects.

Under level-1 thinking, the response of output is identical when prices are rigid and when they are sticky, simply because at this level of reasoning, agents do not expect any inflation even if prices are sticky. It features stronger mitigation and horizon effects, the more incomplete markets are. The same applies to the response of inflation. As $k$ increases, the responses of output and inflation converge monotonically to their rationalexpectations counterparts, but this convergence is markedly slower now, the more incomplete markets are. In the rational-expectations limit which obtain for $k=\infty$, by construction, they become independent of the degree of market incompleteness in our model.

Incomplete markets alone does not change the aggregate responses . Level- $k$ bounded rationality alone mitigates and for low values of $k$ reverses these effects. But even for $k=1$, the horizon effects remain very weak, exactly as in the case of rigid prices considered in Section 5. Level- $k$ bounded rationality and incomplete markets together generate powerful horizon effects, exactly as in the case of rigid prices considered in Section 5 . The complementarity between incomplete markets and bounded rationality that we identified in the case of rigid prices remains and is even strengthened with sticky prices.

Related literature. The intellectual genealogy of the concept of level- $k$ equilibrium is well described in García-Schmidt and Woodford (2015). More generally, and following a categorization proposed by Guesnerie (1992) and adopted by Woodford (2013), our approach belongs to the eductive class of deviations from rational expectations, where one assumes that agents correctly understand the model and form inferences about future outcomes through a process of reflection, independent of experience, and not necessarily occurring in real time. ${ }^{11}$ This class of deviations from rational expectations is distinct from inductive approaches, which assume that the probabilities that people assign to possible

\footnotetext{
${ }^{11}$ This terminology originates in the work of Guesnerie (1992) on "eductive stability".
} 
future outcomes should not be too different from the probabilities with which different outcomes actually occur, given that experience should allow some familiarity with these probabilities, regardless of whether agents understand the way in which these outcomes are generated (models of incomplete information with econometrics learning and models of partially or approximately correct beliefs).

The concept of level- $k$ equilibrium is related to the iterative algorithm proposed by Fair and Taylor (1983) to compute numerically rational-expectations equilibria of a dynamic economic models, with the successive iterations resembling the ones described in the construction of level- $k$ equilibria. The difference that the concept of level- $k$ equilibrium sees the different iterations not simply as steps towards the computation of rationalexpectations equilibria, but as interesting equilibrium concepts per se that can be compared to the data. The concept of level- $k$ equilibrium is closely related to the concept of calculation equilibrium of Evans and Ramey (1992; 1995; 1998), who advocate stopping after a few iterations owing to calculations costs. It is slightly different from the concept of "reflective equilibrium" in García-Schmidt and Woodford (2015) who consider a continuous process whereby expectation are governed by a differential equation in the level of thought rather than my a discrete recursion as we do, but this difference is largely inconsequential.

The concept of level- $k$ thinking has also been proposed to explain behavior in laboratory experiments with games of full information (Stahl and Wilson 1994; O. and W. 1995; Nagel 1995; Crawford et al. 2013). The model specifies a naive form of behavior which is taken to be that of level-0 players. Level- $k$ players use their understanding of the game to calculate their best action on the assumption that other players in the game are level- $k-1$ players. The observed play of many experimental subjects in multi-player games is found to correspond to low levels of reasoning (usually between 0 and 3 ) when the subjects are confronted with a new situation (they have no experience playing the game) but have had the rules explained to them (so that they can compute their best response to a conjecture about other players' expectations). ${ }^{12}$ These experimental games are arguably considerably simpler than the economies that we consider in our paper, and so lower levels of reasoning should be expected in our context.

Our paper also belongs to the growing literature studying the effects of macroeconomic stabilization policy in incomplete-markets models, but maintaining the assumption of rational expectations. Recent examples include Auclert (2017), Caballero and

\footnotetext{
${ }^{12}$ Arad and Rubinstein (2012) argue than even in simple games and with fairly sophisticated agents, few if any exhibit level higher than 3. Camerer et al. (2004) and Crawford et al. (2013) provide other empirical evidence on the levels of thinking in experimental games.
} 
Farhi (2017), Eggertsson and Krugman (2012), Farhi and Werning (2016a,b, 2017), Gali et al. (2007), Guerrieri and Lorenzoni (2015), Kaplan and Violante (2014), Kaplan et al. (2016), Kekre (2016), Oh and Reis (2012), Ravn and Sterk (2016), and Sterk and Tenreyro (2013). In particular, it is closely related to Del Negro et al. (2015) and McKay et al. (2016), who study forward guidance in New Keynesian models with an overlapping generations structure and a Bewley-Aiyagari-Hugget structure respectively. ${ }^{13}$ Werning (2015) shows that their results regarding the limitations of the power of forward guidance are driven by specific assumptions regarding the distribution of profits and the cyclicality of liquidity, and that reasonable benchmarks produce instead a neutrality result whereby incomplete markets per se do no affect the sensitivity of the economy to interest rate changes. In our paper, we make a deliberate effort to make such neutral choices. Thus our results are not driven by incomplete markets

Most closely related to our paper are García-Schmidt and Woodford (2015), Gabaix (2017), Angeletos and Lian (2017), and Wiederholt (2016), who study the effects of monetary policy, and in particular the limits of forward guidance, in standard New Keynesian models with either bounded rationality for the first two of these papers ("reflective equilibrium" and "sparsity" respectively) or full rationality and informational frictions the last two of these papers. An important difference between and these papers and ours is that they maintain the assumption of complete markets while we study incomplete markets. Another important difference between our paper and Angeletos and Lian (2017) and Wiederholt (2016) is that they rely on an inductive approach with informational frictions and full rationality instead of an eductive approach with bounded rationality. In Angeletos and Lian (2017), there is imperfect common knowledge because agents receive private signals about interest rate changes and must forecast the forecasts of others. Wiederholt (2016) also assumes informational frictions but of a different form, by positing that agents have sticky expectations a la Mankiw and Reis (2002) and receive information about interest rate changes after the realization of an idiosyncratic Poisson shock. In contrast to these models with full rationality and informational frictions, ours is one of full information with bounded rationality where agents know the path of interest rates but face difficulties in calculating the macroeconomic equilibrium consequences of changes in interest rates. We think that our approach is better suited to capture the limits of forward guidance in contexts where considerable efforts are made by central banks to communi-

\footnotetext{
${ }^{13}$ Caballero and Farhi (2017) offer a rationalization of the forward guidance puzzle in a model with heterogenous risk aversion where risk-tolerant agents issue safe assets to risk-averse agents through a process of securitization of real risky assets hampered by a securitization constraint. When the securitization constraint is binding, the effectiveness of forward guidance is reduced because the constraint prevents it from increasing the supply of safe assets and hence reduces its ability to stimulate the economy.
} 
cate their policies and where indeed experience shows that the yield curve is very reactive to these announcements.

\section{Level- $k$ in a Simple Reduced-Form Model}

We being by introducing the basic concepts of level- $k$ equilibrium within a simplified model building on a reduced-form aggregate consumption function. Various explicit disaggregated models can be explicitly reduced to this formulation. For example, representativeagent models, overlapping generations models, models with a fraction of permanentincome consumers and a fraction of hand-to-mouth consumers, and Bewley-AiyagariHuggett models of heterogenous agents with income fluctuation and incomplete markets, all give rise to an aggregate consumption function of the form considered below. We will make this mapping explicit for several of these models in future sections.

\subsection{Baseline Reduced-Form Model}

We consider a simple model with one consumption good in every period and no investment. Time is discrete and the horizon is infinite with periods $t=0,1, \ldots$ We denote current and future real nominal interest rates by $\left\{R_{t+s}\right\}$, and current and future aggregate income by $\left\{Y_{t+s}\right\}$, where $s$ runs from 0 to $\infty$. We focus for simplicity on the extreme case with perfectly rigid prices, where real interest rates equal nominal interest rates. We maintain this assumption in Sections 2-5. We take as given the path of nominal interest rates $\left\{R_{t+s}\right\}$ coincides with the path of real interest rates. Our goal is to solve for the equilibrium path of aggregate income $\left\{Y_{t+s}\right\}$. An alternative interpretation is that we are characterizing the response of the economy to different path of real interest rates, which are under the control of the monetary authority because of nominal rigidities. In any case, we relax the assumption of perfectly rigid prices in Section 6 where we consider sticky prices.

Aggregate consumption function. We postulate an aggregate consumption function

$$
C_{t}=C^{*}\left(\left\{R_{t+s}\right\}, Y_{t},\left\{Y_{t+1+s}^{e}\right\}\right)
$$

where $\left\{Y_{t+1+s}^{e}\right\}$ denotes future anticipated aggregate income.

The fact that the aggregate consumption function depends only on current and future interest rates, current income and future anticipated income is useful and merits brief 
discussion. With a representative agent such a formulation is straightforward, and we discuss this example below. Otherwise, the consumption function should be interpreted as performing an aggregation and consolidating any distributional effects, including solving out for wages and profits as a function of current $Y_{t}$. Implicitly we are also assuming there is no heterogeneity in beliefs about future income, $\left\{Y_{t+1+s}^{e}\right\}$, although one may extend the analysis to capture heterogeneity in beliefs.

In this formulation the consumption function is purely forward looking-it does not depend on the past or on any state variable that is affected by the past. This can accommodate various interesting and simple models, such as the representative agent, the perpetual youth overlapping generations model, and certain simple models with heterogeneity such as models fraction of hand-to-mouth agents. It does not fit all situations, however. In the next subsection we provide an extension with an aggregate state variable which allows us to captures standard Bewley-Aiyagari-Huggett models.

Temporary equilibria. We are interested in allowing for more general beliefs than rational expectations. We start by defining the notion of temporary equilibrium in the spirit of Hicks (1939) and Lindahl (1939), and further developed by Grandmont (1977; 1978). A temporary equilibrium takes as given a sequence of beliefs $\left\{Y_{t}^{e}\right\}$ and simply imposes that the goods market clear

$$
Y_{t}=C_{t}
$$

Definition (Temporary equilibrium). Given a sequence of beliefs $\left\{Y_{t}^{e}\right\}$, a temporary equilibrium is a sequence $\left\{R_{t}, Y_{t}\right\}$ satisfying (1) and (2) for all $t \geq 0$.

Start at some baseline temporary equilibrium $\left\{R_{t}, Y_{t}, Y_{t}^{e}\right\}$ and consider the one-time unexpected announcement at $t=0$ of a new interest rate path $\left\{\hat{R}_{t}\right\}$. The equilibrium response depends on the adjustment of beliefs. We now describe two possible adjustments of beliefs: rational expectations and level- $k$ thinking.

Rational-expectations equilibria. A rational-expectations equilibrium is a particular case of temporary equilibrium with the extra requirement of perfect foresight, i.e. that beliefs about future income coincide with actual future income

$$
\left\{Y_{t}^{e}\right\}=\left\{Y_{t}\right\}
$$

Definition (Rational expectation equilibrium). A rational-expectations equilibrium (REE) is a sequence $\left\{R_{t}, Y_{t}, Y_{t}^{e}\right\}$ such that $\left\{R_{t}, Y_{t}\right\}$ is a temporary equilibrium given beliefs $\left\{Y_{t}^{e}\right\}$ and which satisfies perfect foresight (3) for all $t \geq 0$. 
For notational convenience, we often denote a given REE by $\left\{R_{t}, Y_{t}\right\}$ instead of using the more cumbersome notation $\left\{R_{t}, Y_{t}, Y_{t}\right\}$.

Start at some baseline REE $\left\{R_{t}, Y_{t}\right\}$ and consider as above a one-time unexpected announcement at $t=0$ of a new interest rate path $\left\{\hat{R}_{t}\right\}$. Under rational expectations, there is an issue about selection since there are typically several REEs for a given interest rate path $\left\{\hat{R}_{t}\right\}$. In our detailed applications, and for the considered interest rate paths, we will always be able to select a unique REE by imposing that the baseline and new REEs coincide in the long run:

$$
\lim _{t \rightarrow \infty} \hat{Y}_{t}=\lim _{t \rightarrow \infty} Y_{t}
$$

From now on, we always use this selection.

Level- $k$ equilibria. We now deviate from rational expectations and describe an alternative adjustment of expectations encapsulated in the notion of level- $k$ thinking. We then introduce the notion of level- $k$ equilibrium $\left\{R_{t}, \hat{Y}_{t}^{k}\right\}$ which specifies a sequence of beliefs $\left\{\hat{Y}_{t}^{e, k}\right\}$ indexed by $k$. As above, we start at some baseline REE $\left\{R_{t}, Y_{t}\right\}$, and consider a one-time unexpected shock change in the path for the interest rate $\left\{\hat{R}_{t}\right\}$ at $t=0$.

The level-1 equilibrium $\left\{\hat{R}_{t}, \hat{Y}_{t}^{1}\right\}$ is a temporary equilibrium given beliefs $\left\{\hat{Y}_{t}^{e, 1}\right\}=$ $\left\{Y_{t}\right\}$ corresponding to the aggregate income path of the original REE. In other words, expectations for future aggregate income are unchanged after the announced change in interest rates and equal to the original REE path. For each each $t=0,1, \ldots, \hat{Y}_{t}^{1}$ can be computed as the following fixed point equation

$$
\hat{Y}_{t}^{1}=C^{*}\left(\left\{\hat{R}_{t+s}\right\}, \hat{Y}_{t}^{1},\left\{Y_{t+1+s}\right\}\right) .
$$

The level-1 equilibrium captures a situation where agents take into account the new announced path for interest rates and observe present income, but do not adjust their expectations about future income. However, actual realized income is affected.

The level-2 equilibrium $\left\{\hat{R}_{t}, \hat{Y}_{t}^{2}\right\}$ is a temporary equilibrium given beliefs $\left\{\hat{Y}_{t}^{e, 2}\right\}=$ $\left\{\hat{Y}_{t}^{1}\right\}$ corresponding to the aggregate income path from level-1. For every $t \geq 0, \hat{Y}_{t}^{2}$ can be computed as the following fixed point equation

$$
\hat{Y}_{t}^{2}=C^{*}\left(\left\{\hat{R}_{t+s}\right\}, \hat{Y}_{t}^{2},\left\{\hat{Y}_{t+1+s}^{1}\right\}\right) .
$$

Here agents update their beliefs to take into account that the change in aggregate spending (by all other agents) associated with level-1 thinking has an effect on aggregate income (and hence on their own income). In other words, level-2 thinking incorporates the 
general equilibrium effects of future income from level 1.

Continuing, the level- $k$ equilibrium $\left\{\hat{R}_{t}, \hat{Y}_{t}^{k}\right\}$ is defined as a temporary equilibrium given beliefs $\left\{\hat{Y}_{t}^{e, k}\right\}=\left\{\hat{Y}_{t}^{e, k-1}\right\}$ corresponding to the aggregate income path of the level$k-1$ equilibrium in a similar manner. Thus, $\hat{Y}_{t}^{k}$ solves the fixed point equation

$$
\hat{Y}_{t}^{k}=C^{*}\left(\left\{\hat{R}_{t+s}\right\}, \hat{Y}_{t}^{k},\left\{\hat{Y}_{t+1+s}^{k-1}\right\}\right) .
$$

Definition (Level-k equilibrium). Given an initial REE $\left\{R_{t}, Y_{t}\right\}$ and a new interest rate path $\left\{\hat{R}_{t}\right\}$, the level- $k$ equilibrium $\left\{R_{t}, \hat{Y}_{t}^{k}\right\}$ is defined by a recursion indexed by $k \geq 0$ with initial condition $\left\{\hat{Y}_{t}^{0}\right\}=\left\{Y_{t}\right\}$, and such that $\left\{\hat{R}_{t}, \hat{Y}_{t}^{k}\right\}$ is a temporary equilibrium given beliefs $\left\{\hat{Y}_{t}^{e, k}\right\}=$ $\left\{\hat{Y}_{t}^{k-1}\right\}$.

In the definitions of temporary and level- $k$ equilibria, we include the actual present aggregate income, instead of some expectation over current aggregate income. This implies that markets clear in the present period and that basic macroeconomic identities hold. This impact of current aggregate income, however, will vanish in some cases in continuous time.

Note that in contrast to rational-expectations equilibria, there is no issue of equilibrium selection in level- $k$ equilibria. The initial REE equilibrium $\left\{R_{t}, Y_{t}\right\}$ acts as an anchor which ensures that the construction of the level- $k$ equilibrium associated with a new interest rate path $\left\{\hat{R}_{t}\right\}$ is determinate.

Decomposing equilibrium changes: PE and GE. Start at some baseline REE $\left\{R_{t}, Y_{t}\right\}$ and consider as above an one-time unexpected announcement at $t=0$ of a new interest rate path $\left\{\hat{R}_{t}\right\}$.

Under rational expectations, the new equilibrium $\left\{\hat{R}_{t}, \hat{Y}_{t}\right\}$ is an REE. We can decompose the change in aggregate income

$$
\Delta Y_{t}=\hat{Y}_{t}-Y_{t}
$$

as

$$
\Delta Y_{t}=\Delta Y_{t}^{P E}+\Delta Y_{t}^{G E}
$$

where

$$
\begin{aligned}
& \Delta Y_{t}^{P E}=C^{*}\left(\left\{\hat{R}_{t+s}\right\}, Y_{t},\left\{Y_{t+1+s}\right\}\right)-C^{*}\left(\left\{R_{t+s}\right\}, Y_{t},\left\{Y_{t+1+s}\right\}\right), \\
& \Delta Y_{t}^{G E}=C^{*}\left(\left\{\hat{R}_{t+s}\right\}, \hat{Y}_{t},\left\{\hat{Y}_{t+1+s}\right\}\right)-C^{*}\left(\left\{\hat{R}_{t+s}\right\}, Y_{t},\left\{Y_{t+1+s}\right\}\right) .
\end{aligned}
$$


The term $\Delta Y_{t}^{P E}$ can be interpreted as a partial equilibrium effect considering only the change in interest rates, holding constant current and future income. The term $\Delta Y_{t}^{G E}$ captures the general equilibrium effects from changing current and future expected income, holding interest rates fixed at their new level.

Under level- $k$ thinking, we denote the change in aggregate income by

$$
\Delta Y_{t}^{k}=\hat{Y}_{t}^{k}-Y_{t}
$$

We can again use a decomposition

$$
\Delta Y_{t}^{k}=\Delta Y_{t}^{P E}+\Delta Y_{t}^{k, G E}
$$

with

$$
\Delta Y_{t}^{k, G E}=C^{*}\left(\left\{\hat{R}_{t+s}\right\}, \hat{Y}_{t}^{k},\left\{\hat{Y}_{t+1+s}^{k-1}\right\}\right)-C^{*}\left(\left\{\hat{R}_{t+s}\right\}, Y_{t},\left\{Y_{t+1+s}\right\}\right) .
$$

In particular, since $\left\{\hat{Y}_{t}^{0}\right\}=\left\{Y_{t}\right\}$, the only reason why $\Delta Y_{t}^{1, G E}=C^{*}\left(\left\{\hat{R}_{t+s}\right\}, \hat{Y}_{t}^{1},\left\{Y_{t+1+s}\right\}\right)-$ $C^{*}\left(\left\{\hat{R}_{t+s}\right\}, Y_{t},\left\{Y_{t+1+s}\right\}\right)$ is not zero is due to the effect of the adjustment of current income $\hat{Y}_{t}^{1}$. As we shall see, this difference vanishes in some cases in continuous time. In these cases, level-1 thinking coincides exactly with the partial equilibrium effect.

Effects of monetary policy at different horizons. To summarize the effects of monetary policy at different horizons, we define the elasticities of output at date $t$ to an interest rate change at date $\tau$ as follows.

We consider an initial REE $\left\{R_{t}, Y_{t}\right\}$ which for simplicity we assume is a steady state with $R_{t}=R$ and $Y_{t}=Y$ for all $t \geq 0$. We consider a change $\left\{\hat{R}_{t}\right\}$ in the path for the interest rate $\Delta R_{\tau}$ at date $\tau$ so that $\hat{R}_{\tau}=R+\Delta R_{\tau}$ and $\hat{R}_{t}=R_{t}$ for $t \neq \tau$. The rationalexpectations elasticity is defined as

$$
\epsilon_{t, \tau}=\lim _{\Delta R_{\tau} \rightarrow 0}-\frac{R_{\tau}}{Y_{t}} \frac{\Delta Y_{t}}{\Delta R_{\tau}}
$$

and can be decomposed as

$$
\epsilon_{t, \tau}=\epsilon_{t, \tau}^{P E}+\epsilon_{t, \tau}^{G E}
$$


where

$$
\begin{aligned}
\epsilon_{t, \tau}^{P E} & =\lim _{\Delta R_{\tau} \rightarrow 0}-\frac{R_{\tau}}{Y_{t}} \frac{\Delta Y_{t}^{P E}}{\Delta R_{\tau}} \\
\epsilon_{t, \tau}^{G E} & =\lim _{\Delta R_{\tau} \rightarrow 0}-\frac{R_{\tau}}{Y_{t}} \frac{\Delta Y_{t}^{G E}}{\Delta R_{\tau}} .
\end{aligned}
$$

Similarly, the level- $k$ elasticity is defined as

$$
\epsilon_{t, \tau}^{k}=\lim _{\Delta R_{\tau} \rightarrow 0}-\frac{R_{\tau}}{Y_{t}} \frac{\Delta Y_{t}^{k}}{\Delta R_{\tau}} .
$$

An immediate consequence of the fact that the aggregate model is purely forward looking is that all these elasticities are zero whenever $t>\tau$. We will therefore focus on the case where $t \leq \tau$.

\subsection{Extended Model with an Aggregate State Variable}

The previous analysis is sufficient for the simplest cases, such as the representative agent and the perpetual youth overlapping generations models. Aggregate consumption is purely forward looking in these cases. However, in an incomplete-markets Bewley-AiyagariHuggett economy, the distribution of wealth induces a backward looking component. To incorporate these effects we now extend the analysis to include an aggregate state variable.

Suppose that aggregate consumption is given by

$$
C_{t}=C^{*}\left(\left\{R_{t+s}\right\}, Y_{t},\left\{Y_{t+1+s}^{e}\right\}, \Psi_{t}\right)
$$

where the state variable $\Psi_{t}$ is potentially of a large dimension and evolves according to some equilibrium law of motion

$$
\Psi_{t+1}=M\left(\left\{R_{t+s}\right\}, Y_{t},\left\{Y_{t+1+s}^{e}\right\}, \Psi_{t}\right)
$$

The initial state $\Psi_{0}$ is taken as given. In incomplete-markets economies, $\Psi_{t}$ may capture the distribution of wealth and $M$ the evolution of the wealth distribution. The important point is that the aggregate consumption function is no longer purely forward looking.

We can easily extend all our definitions. A temporary equilibrium given beliefs $\left\{Y_{t}^{e}\right\}$ is a set of sequences $\left\{R_{t}, Y_{t}, \Psi_{t}\right\}$ satisfying (2), (4), and (5) for all $t \geq 0$. An REE is a set of sequences $\left\{R_{t}, Y_{t}, Y_{t}^{e}, \Psi_{t}\right\}$ such that $\left\{R_{t}, Y_{t}, \Psi_{t}\right\}$ is a temporary equilibrium given beliefs 
$\left\{Y_{t}^{e}\right\}$ and which satisfies perfect foresight (3) for all $t=0,1, \ldots$ Given a baseline REE and a one-time unexpected announced at $t=0$ of a new interest rate path $\left\{\hat{R}_{t}\right\}$, level- $k$ equilibria $\left\{\hat{R}_{t}, \hat{Y}_{t}^{k}, \hat{\Psi}_{t}^{k}\right\}$ are defined by a recursion indexed by $k \geq 0$ with initial condition $\left\{\hat{Y}_{t}^{0}\right\}=\left\{Y_{t}\right\}$, and such that $\left\{\hat{R}_{t}, \hat{Y}_{t}^{k}, \hat{\Psi}_{t}^{k}\right\}$ is a temporary equilibrium given beliefs $\left\{\hat{Y}_{t}^{e, k}\right\}=$ $\left\{\hat{Y}_{t}^{k-1}\right\}$. Armed with these definitions, it is straightforward to extend the definitions of the elasticities $\epsilon_{t, \tau}, \epsilon_{t, \tau}^{P E}, \epsilon_{t, \tau}^{G E}$, and $\epsilon_{t, \tau}^{k}$. Since the model is no longer necessarily purely forward looking, it is no longer necessarily true that all these elasticities are zero for $t>\tau$.

\section{The Representative-Agent Model}

In this section, we consider the particular case of a representative-agent model with per period utility function $U$ in a Lucas tree economy with a unit supply of Lucas trees with time- $t$ value $V_{t}$ capitalizing a stream $\delta Y_{t}$ of dividends and with non-financial (labor) income given by $(1-\delta) Y_{t}$. The representative agent can invest in Lucas trees and also borrow and lend in short-term risk-free bonds with the sequence of interest rates $\left\{R_{t}\right\}$. At every point in time $t$, the agents has beliefs $\left\{Y_{t+1+s}^{e}, V_{t+1+s}^{e}\right\}$ about future aggregate income and values of Lucas trees.

In Section 3.1, we show how to derive the reduced-form aggregate consumption function from the consumption policy function of an individual problem using the asset market clearing condition for a general utility function. We then leverage all the definitions of Section 2.1: temporary equilibria, rational-expectations equilibria, level- $k$ equilibria, and the corresponding interest rate elasticities. In Section 3.2, we specialize the model to the case of an isoelastic utility function and derive analytical results.

\subsection{The General Representative-Agent Model}

In this section, we consider a general utility function $U$.

Individual problem. Consider sequences $\left\{R_{t}, Y_{t}, Y_{t}^{e}, V_{t}, V_{t}^{e}\right\}$. An individual takes these sequences as given. At every point in time $t$, current consumption $c_{t}$, current bond and Lucas tree holdings $b_{t}$ and $x_{t}$ are determined as a function of past bond and Lucas tree holdings $b_{t-1}$ and $x_{t-1}$ via the individual policy functions

$$
\begin{aligned}
& c_{t}=c^{*}\left(b_{t-1}, x_{t-1} ;\left\{R_{t+s}\right\}, Y_{t},\left\{Y_{t+1+s}^{e}\right\}, V_{t},\left\{V_{t+1+s}^{e}\right\}\right), \\
& b_{t}=b^{*}\left(b_{t-1}, x_{t-1} ;\left\{R_{t+s}\right\}, Y_{t},\left\{Y_{t+1+s}^{e}\right\}, V_{t},\left\{V_{t+1+s}^{e}\right\}\right), \\
& x_{t}=x^{*}\left(b_{t-1}, x_{t-1} ;\left\{R_{t+s}\right\}, Y_{t},\left\{Y_{t+1+s}^{e}\right\}, V_{t},\left\{V_{t+1+s}^{e}\right\}\right) .
\end{aligned}
$$


This defines a recursion over $t$, which together with the initial conditions $b_{-1}=0$ and $x_{-1}=1$, entirely determines individual sequences $\left\{c_{t}, b_{t}, x_{t}\right\}$.

The individual policy functions at time $t$ are derived from the following individual problem at time $t$, given $b_{t-1}$ and $x_{t-1}$ :

$$
\max _{\left\{\tilde{c}_{t+s}, \tilde{b}_{t+s}, \tilde{x}_{t+s}\right\}} \sum_{s=0}^{\infty} \beta^{s} U\left(\tilde{c}_{t+s}\right)
$$

subject to the current actual budget constraint

$$
\tilde{c}_{t}=(1-\delta) Y_{t}+x_{t-1} V_{t}+b_{t-1} R_{t-1}-\tilde{x}_{t} V_{t}-\tilde{b}_{t}
$$

and future expected budget constraints

$$
\tilde{c}_{t+1+s}=(1-\delta) Y_{t+1+s}^{e}+\tilde{x}_{t+s} V_{t+1+s}^{e}+\tilde{b}_{t+s} R_{t+s}-\tilde{x}_{t+1+s} V_{t+1+s}^{e}-\tilde{b}_{t+1+s} \quad \forall s \geq 0 .
$$

We define $c^{*}\left(b_{t-1}, x_{t-1} ;\left\{R_{t+s}\right\}, Y_{t},\left\{Y_{t+1+s}^{e}\right\}, V_{t},\left\{V_{t+1+s}^{e}\right\}\right)$, to be the value of $\tilde{c}_{t}$ at the optimum. Similarly, $b^{*}\left(b_{t-1}, x_{t-1} ;\left\{R_{t+s}\right\}, Y_{t},\left\{Y_{t+1+s}^{e}\right\}, V_{t},\left\{V_{t+1+s}^{e}\right\}\right)$ is the value of $\tilde{b}_{t}$ at the optimum, and $x^{*}\left(b_{t-1}, x_{t-1} ;\left\{R_{t+s}\right\}, Y_{t},\left\{Y_{t+1+s}^{e}\right\}, V_{t},\left\{V_{t+1+s}^{e}\right\}\right)$ is the value of $\tilde{x}_{t}$ at the optimum. These values satisfy the current actual budget constraint. ${ }^{14}$

We now simplify these steps by imposing the following necessary no arbitrage conditions for the individual problems to have a solution:

$$
\begin{aligned}
V_{t} & =\delta Y_{t}+\frac{V_{t+1}^{e}}{R_{t}} \quad \forall t \geq 0, \\
V_{t}^{e} & =\delta Y_{t}^{e}+\sum_{s=0}^{\infty} \frac{\delta Y_{t+1+s}^{e}}{\prod_{u=0}^{s} R_{t+u}} \quad \forall t \geq 0 .
\end{aligned}
$$

Given no arbitrage, an individual agents is indifferent between bonds and Lucas trees, and the composition of his portfolio is indeterminate. Accordingly, we define a new variable $a_{t}=b_{t-1} R_{t-1}+x_{t-1}\left(\delta Y_{t}+V_{t}\right)$ denoting financial wealth at time $t$.

We can then simplify the individual problem at time $t$ :

$$
\max _{\left\{\tilde{c}_{t}, \tilde{\tilde{a}}_{t+1+s}\right\}} \sum_{s=0}^{\infty} \beta^{s} U\left(\tilde{c}_{t+s}\right)
$$

\footnotetext{
${ }^{14}$ Importantly, note that at the optimum $\left\{\tilde{c}_{t+1+s}, \tilde{b}_{t+1+s}, \tilde{x}_{t+1+s}\right\}$ is in general different from $\left\{c_{t+1+s}, b_{t+1+s}, x_{t+1+s}\right\}$. This is a symptom of time inconsistency when beliefs deviate from rational expectations.
} 
subject to the current actual budget constraint

$$
\tilde{c}_{t}=(1-\delta) Y_{t}+a_{t}-\frac{\tilde{a}_{t+1}}{R_{t}}
$$

and future expected budget constraints

$$
\tilde{c}_{t+1+s}=(1-\delta) Y_{t+1+s}^{e}+\tilde{a}_{t+1+s}-\frac{\tilde{a}_{t+2+s}}{R_{t+1+s}} \quad \forall s \geq 0,
$$

We denote by $c^{*}\left(a_{t} ;\left\{R_{t+s}\right\}, Y_{t},\left\{Y_{t+1+s}^{e}\right\}\right)$ and $a^{*}\left(a_{t} ;\left\{R_{t+s}\right\}, Y_{t},\left\{Y_{t+1+s}^{e}\right\}\right)$ the individual policy functions of the individual problem at time $t$. They are given by the values of time- $t$ consumption $\tilde{c}_{t}$ and time- $t+1$ assets $\tilde{a}_{t+1}$ at the individual optimum. These values satisfy the current actual time- $t$ budget constraint. Note that $V_{t}$ and $\left\{V_{t+1+s}^{e}\right\}$ are no longer arguments of these policy functions, a very convenient simplification.

At every point in time $t$, current consumption $c_{t}$ and financial wealth $a_{t+1}$ are determined as a function of past financial wealth $a_{t}$ via the individual policy functions

$$
\begin{aligned}
c_{t} & =c^{*}\left(a_{t} ;\left\{R_{t+s}\right\}, Y_{t},\left\{Y_{t+1+s}^{e}\right\}\right), \\
a_{t+1} & =a^{*}\left(a_{t} ;\left\{R_{t+s}\right\}, Y_{t},\left\{Y_{t+1+s}^{e}\right\}\right) .
\end{aligned}
$$

This defines a recursion over $t$, which together with the initial conditions $a_{0}=V_{0}$, entirely determines the individual sequences $\left\{c_{t}, a_{t}\right\}$.

Reduced-form aggregate consumption function. The reduced-form aggregate consumption is obtained from the individual consumption function $C\left(\left\{R_{t+s}\right\}, Y_{t},\left\{Y_{t+1+s}^{e}\right\}\right)=$ $c\left(a_{t} ;\left\{R_{t+s}\right\}, Y_{t},\left\{Y_{t+1+s}^{e}\right\}\right)$ by imposing the asset market clearing condition $a_{t}=V_{t}$, where $V_{t}$ is given by the no-arbitrage condition (6). This yields

$$
C\left(\left\{R_{t+s}\right\}, Y_{t},\left\{Y_{t+1+s}^{e}\right\}\right)=c^{*}\left(\delta Y_{t}+\sum_{s=1}^{\infty} \frac{\delta Y_{t+1}^{e}}{\prod_{u=0}^{s} R_{t+u}} ;\left\{R_{t+s}\right\}, Y_{t},\left\{Y_{t+1+s}^{e}\right\}\right) .
$$

We can then use this reduced-form aggregate consumption function to go through all the definitions given in Section 2: temporary equilibria, rational-expectations equilibria, level- $k$ equilibria, and the corresponding interest rate elasticities. 


\subsection{Isoelastic Utility Function}

In this section, we specialize the model to the case of an isoelastic utility function with intertemporal elasticity of substitution $\sigma$ :

$$
U(c)=\left\{\begin{array}{lll}
\frac{c^{1-\frac{1}{\sigma}}-1}{1-\frac{1}{\sigma}} & \text { if } & \sigma \neq 1 \\
\log (c) & \text { if } & \sigma=1
\end{array}\right.
$$

It is then easy to see that the individual consumption function is

$$
c^{*}\left(a_{t} ;\left\{R_{t+s}\right\}, Y_{t},\left\{Y_{t+1+s}^{e}\right\}\right)=\frac{a_{t}+(1-\delta) Y_{t}+\sum_{s=0}^{\infty} \frac{(1-\delta) Y_{t+1+s}^{e}}{\Pi_{u=0}^{s} R_{t+u}}}{1+\sum_{s=0}^{\infty} \frac{\beta^{\sigma(1+s)}}{\Pi_{u=0}^{s} R_{t+u} R^{1-\sigma}}}
$$

so that the aggregate reduced-form consumption function is

$$
C\left(\left\{R_{t+s}\right\}, Y_{t},\left\{Y_{t+1+s}^{e}\right\}\right)=\frac{Y_{t}+\sum_{s=0}^{\infty} \frac{Y_{t+1+s}^{e}}{\prod_{u=0}^{s} R_{t+u}}}{1+\sum_{s=0}^{\infty} \frac{\beta^{\sigma(1+s)}}{\prod_{u=0}^{s} R_{t+u}^{1-\sigma}}}
$$

Equilibrium characterization. For concreteness, we briefly characterize the various equilibria in the context of this particular model. Given beliefs $\left\{Y_{t}^{e}\right\}$, and given the path for interest rates $\left\{R_{t}\right\},\left\{R_{t}, Y_{t}\right\}$ is a temporary equilibrium if and only if the path for aggregate income $\left\{Y_{t}\right\}$ is given by

$$
Y_{t}=\frac{\sum_{s=0}^{\infty} \frac{Y_{t+1+s}^{e}}{\prod_{u=0}^{s} R_{t+u}}}{\sum_{s=0}^{\infty} \frac{\beta^{\sigma(1+s)}}{\prod_{u=0}^{s} R_{t+u}-\sigma}} \quad \forall t \geq 0
$$

Similarly, given the path for interest rates $\left\{R_{t}\right\},\left\{R_{t}, Y_{t}\right\}$ is an REE if and only if the path for aggregate income $\left\{Y_{t}\right\}$ satisfies the fixed point

$$
Y_{t}=\frac{\sum_{s=0}^{\infty} \frac{Y_{t+1+s}}{\prod_{u=0}^{s} R_{t+u}}}{\sum_{s=0}^{\infty} \frac{\beta^{\sigma(1+s)}}{\prod_{u=0}^{s} R_{t+u}{ }^{1-\sigma}}} \quad \forall t \geq 0
$$


Finally given an initial REE $\left\{R_{t}, Y_{t}\right\}$ and a new interest rate path $\left\{\hat{R}_{t}\right\}$, the level-k equilibria $\left\{\hat{R}_{t}, \hat{Y}_{t}^{k}\right\}$ satisfy the following recursion over $k \geq 0$ :

$$
\hat{Y}_{t}^{k}=\frac{\sum_{s=0}^{\infty} \frac{\hat{\Upsilon}_{t+1+s}^{k-1}}{\prod_{u=0}^{s} \hat{R}_{t+u}}}{\sum_{s=0}^{\infty} \frac{\beta^{\sigma(1+s)}}{\prod_{u=0}^{s} \hat{R}_{t+u}{ }^{1-\sigma}}} \quad \forall t \geq 0,
$$

with the initialization that $\hat{Y}_{t}^{0}=Y_{t}$ for all $t \geq 0$.

We now turn to the computation of the different interest rate elasticities of output around a steady state REE $\left\{R_{t}, Y_{t}\right\}$ with $R_{t}=R=\beta^{-1}>1$ and $Y_{t}=Y>0$ for all $t \geq 0$.

Monetary policy at different horizons under RE. We start with the RE case, where as discussed above, we use the selection that $\lim _{t \rightarrow \infty} Y_{t}=Y$ as we perform the comparative statics underlying the computation of the interest rate elasticities of output.

Proposition 1 (Representative agent, isoelastic utility, RE). Consider the representative-agent model with isoelastic utility and rational expectations. For $t>\tau$ the interest rate elasticities of output are zero $\epsilon_{t, \tau}=0$. For $t \leq \tau$, they depend only on the horizon $\tau-t$ and are given by

$$
\epsilon_{t, \tau}=\sigma
$$

They can be decomposed as $\epsilon_{t, \tau}=\epsilon_{t, \tau}^{P E}+\epsilon_{t, \tau}^{G E}$ into PE and GE elasticities $\epsilon_{t, \tau}^{P E}$ and $\epsilon_{t, \tau}^{G E}$. For $t>\tau$ these elasticities are zero $\epsilon_{t, \tau}^{P E}=\epsilon_{t, \tau}^{G E}=0$. For $t \leq \tau$, they depend only on the horizon $\tau-t$ and are given by

$$
\epsilon_{t, \tau}^{P E}=\sigma \frac{1}{R^{\tau-t+1}} \quad \text { and } \quad \epsilon_{t, \tau}^{G E}=\sigma\left(1-\frac{1}{R^{\tau-t+1}}\right) .
$$

Because the aggregate model is purely forward looking, the interest rate elasticity $\epsilon_{t, \tau}$ of output at date $t$ to interest rate changes at date $\tau$ is zero for $t>\tau$. From now on we focus on $t \leq \tau$ and we call $\tau-t$ the horizon of monetary policy.

The total interest rate elasticity of output is equal to the intertemporal elasticity of substitution $\epsilon_{t, \tau}=\sigma$, independently of the horizon $\tau-t$. This lack of horizon effect is a version of the "forward guidance puzzle", which refers to the extreme effectiveness of forward guidance (interest rate changes in the future) in standard New-Keynesian models compared to its apparently more limited effectiveness in the data.

To understand this result, it it useful to go back to the decomposition into PE and GE effects. The lack of horizon effect

$$
\frac{\partial \epsilon_{t, \tau}}{\partial \tau}=0
$$


can be understood as follows, where, slightly abusing notation, we write $\frac{\partial \epsilon_{t, \tau}}{\partial \tau}$ for $\epsilon_{t, \tau+1}-$ $\epsilon_{t, \tau}$. The PE effect does feature a horizon effect so that $\epsilon_{t, \tau}^{P E}$ is decreasing with the horizon $\tau-t$ with

$$
\frac{\partial \epsilon_{t, \tau}^{P E}}{\partial \tau}=-\log (R) \epsilon_{t, \tau}^{P E}<0
$$

This is because for a given path of output, a cut in interest rates is more discounted, and hence leads to a smaller partial equilibrium consumption increase, the further into the future the interest rate cut takes place. But the GE effect features an exactly offsetting anti-horizon effect so that $\epsilon_{t, \tau}^{G E}$ increases with the horizon $\tau-t$ with

$$
\frac{\partial \epsilon_{t, \tau}^{G E}}{\partial \tau}=-\frac{\partial \epsilon_{t, \tau}^{P E}}{\partial \tau}>0
$$

This is because in general equilibrium, output increases for a longer time, up until the horizon of the interest rate cut, leading to a higher increase in human and financial wealth, the further into the future the interest rate cut takes place, and hence leads to a larger consumption increase. As a result, the relative importance of the GE effect increases with the horizon, and that of the PE effect correspondingly decreases with the horizon, but the two effects always sum up to a constant total effect.

Monetary policy at different horizons under level- $k$. We now turn to the level- $k$ case. We start by defining the function

$$
\mathcal{E}^{k}(R-1, \tau-t)=\sum_{m=0}^{k-1}(R-1)^{m} \sum_{s_{0}=0}^{\tau-t-1} \sum_{s_{1}=0}^{\tau-t-1-s_{0}} \cdots \sum_{s_{m-2}=0}^{\tau-t-1-s_{m-3}} 1 .
$$

The function $\mathcal{E}^{k}$ is increasing in $k$ with $\mathcal{E}^{1}(R-1, \tau-t, 1)=1$ and $\lim _{k \rightarrow \infty} \mathcal{E}^{k}(R-1, \tau-$ $t)=R^{\tau-t} \cdot 15$

Proposition 2 (Representative agent, level- $k$ ). Consider the representative-agent model with isoelastic utility and level-k thinking. For $t>\tau$ the interest rate elasticities of output are zero

\footnotetext{
${ }^{15}$ It is also useful to compute a few other examples explicitly. We have

$$
\begin{aligned}
& \mathcal{E}^{1}(R-1, \tau-t, 1)=1 \\
& \mathcal{E}^{2}(R-1, \tau-t, 2)=1+(R-1)(\tau-t), \\
& \mathcal{E}^{3}(R-1, \tau-t, 3)=1+(R-1)(\tau-t)+\frac{(R-1)^{2}(\tau-t-1)(\tau-t)}{2} .
\end{aligned}
$$
}


$\epsilon_{t, \tau}^{k}=0$. For $t \leq \tau$, they depend only on the horizon $\tau-t$ and are given by

$$
\epsilon_{t, \tau}^{k}=\sigma \frac{\mathcal{E}^{k}(R-1, \tau-t)}{R^{\tau-t}} .
$$

As above, we focus on the interesting case $t \leq \tau$. To begin with, note that the interest rate elasticity of output with level- $k$ thinking converges to its rational-expectations counterpart in the limit $k \rightarrow \infty$ :

$$
\lim _{k \rightarrow \infty} \epsilon_{t, \tau}^{k}=\epsilon_{t, \tau} .
$$

The rational-expectations case can therefore be seen as a limit case of level- $k$ thinking as the number of rounds $k$ goes to $\infty$. Recall that the treatment of rational expectations required an equilibrium selection, whereas that of the level- $k$ case did not. Hence one can also see the convergence of the level- $k$ equilibrium to the particular rational-expectations limit as a validation of the equilibrium selection that underpinned its construction.

Next recall that the PE effect is always the same under rational expectations and under level- $k$ thinking at $\epsilon_{t, \tau}^{P E}$. The level-1 elasticity is always higher than the PE effect by a factor of $R$ since

$$
\epsilon_{t, \tau}^{1}=\sigma \frac{1}{R^{\tau-t}}=R \epsilon_{t, \tau}^{P E}>\epsilon_{t, \tau}^{P E}
$$

but as we shall see below, the difference $\epsilon_{t, \tau}^{1, G E}=\epsilon_{t, \tau}^{1}-\epsilon_{t, \tau}^{P E}$ vanishes in the continuous time limit where time periods become infinitesimal so that the per-period interest rate $R$ shrinks to 1 . The interest rate elasticity of output with level- $k$ thinking is lower than under rational expectations

$$
\epsilon_{t, \tau}^{k}<\epsilon_{t, \tau},
$$

but increases with the level $k$ of thought

$$
\frac{\partial \epsilon_{t, \tau}^{k}}{\partial k}>0
$$

and as noted above, converges monotonically to its rational-expectations counterpart in the limit when $k$ goes to $\infty$, where, slightly abusing notation, we write $\frac{\partial \epsilon_{t, \tau}^{k}}{\partial k}$ for $\epsilon_{t, \tau}^{k+1}-\epsilon_{t, \tau}^{k+1}$. The mitigation effect $\epsilon_{t, \tau}^{k}<\epsilon_{t, \tau}$ is entirely due to a mitigation of the GE effect $\epsilon_{t, \tau}^{k, G E}<\epsilon_{t, \tau}^{G E}$. Similarly, the monotonically increasing convergence $\lim _{k \rightarrow \infty} \epsilon_{t, \tau}^{k}=\epsilon_{t, \tau}$ is entirely due to the monotonically increasing convergence of the GE effect $\lim _{k \rightarrow \infty} \epsilon_{t, \tau}^{k, G E}=\epsilon_{t, \tau}^{G E}$.

In addition, for any $k>0$, in contrast to the rational-expectations case, there is now a horizon effect of monetary policy

$$
\frac{\partial \epsilon_{t, \tau}^{k}}{\partial \tau}<0
$$


so that the effects of monetary policy decrease with its horizon. This horizon effect disappears in the rational-expectations limit when $k$ goes to $\infty$.

However the mitigation and horizon effects are rather weak. To see this focus on the case $k=1$. Then $\epsilon_{t, \tau}^{1}=\sigma \frac{1}{R^{\tau-t}}$ and so

$$
\frac{\partial \epsilon_{t, \tau}^{1}}{\partial \tau}=-\log (R) \epsilon_{t, \tau}^{1}
$$

Hence $\epsilon_{t, \tau}^{1}=\epsilon_{t, \tau}$ when the interest rate change is contemporaneous $\tau-t=0$, and then $\epsilon_{t, \tau}^{1}$ decreases with the horizon $\tau-t$ at the exponential rate $\log (R)$ while $\epsilon_{t, \tau}=\sigma$ stays constant. We call $\log (R)$ the strength of the horizon effect. If the annual interest rate is $5 \%$, the effects of monetary policy decrease at rate $5 \%$ per year with a half life of 14 years; if the annual interest rate is $1 \%$, the effects of monetary policy decrease at rate $1 \%$ per year with a half life of 69 years.

There is a simple intuition for all these results in terms of the decomposition of the effects of monetary policy into PE and GE effects. The PE effect features mitigation-the effect of interest rate changes is lower than the full effect under rational expectations because the latter is the sum of the GE and the PE effect. It also features horizon-for a fixed path of output, interest rate changes affect partial equilibrium consumption less, the further in the future they are. These effects are weak for reasonable values of $R$. As we shall see below, this last conclusion can be overturned in models with heterogenous agents and incomplete markets.

Under rational expectations, the GE effect eliminates the mitigation feature by adding to the PE effect, and eliminates the horizon effect because the GE effect features an antihorizon effect. At round $k=1$, monetary policy almost (exactly in the continuous time limit) coincides with the PE effect and features weak mitigation and weak horizon. In the rational-expectations limit when $k$ goes to $\infty$, the mitigation and horizon effects disappear. Intermediate values of $k$ interpolate smoothly and monotonically between these two extremes.

It is also interesting to note that the various interest rate elasticities of output are all independent of the amount of outside liquidity $\delta$. This is because human and financial wealth play very similar roles in this representative-agent model. As we shall see shortly, this irrelevance breaks down in heterogenous agents models with incomplete markets. 


\subsection{Continuous-Time Limit}

We now explain how the results can be adapted in continuous time. This can be done either directly by setting up the model in continuous time, or by taking the continuoustime limit of the discrete time model. In Section 4, we follow the former approach. In this section instead, we follow the latter.

The continuous-time limit involves considering a sequence of economies indexed by $n \geq 0$, where the calendar length $\lambda_{n}$ of a period decreases with $n$. For example, we can take $\lambda_{n}=\frac{1}{n}$. We keep the discount factor constant per unit of calendar time as we increase $n$ requires by imposing that the discount factor per period equal $\beta_{n}=e^{\rho \lambda_{n}}$ for some instantaneous discount rate $\rho$. The steady-state interest rate is then constant per unit of calendar time as we increase $n$, but the interest rate per period is $R_{n}=e^{r \lambda_{n}}$ for the instantaneous interest rate $r=\rho$. This naturally implies that $\lim _{n \rightarrow \infty} \beta_{n}=\lim _{n \rightarrow \infty} R_{n}=$ 1. Note that a given calendar date $t$ corresponds to a different period number $t_{n}(t)=\frac{t}{\lambda_{n}}$ for different values of $n$.

We can then apply our definitions from the previous sections for every value of $n$ and take the limit as $n$ goes to $\infty$. For fixed calendar date $t$ and $\tau$, we can compute the limits of $\epsilon_{t_{n}(t), t_{n}(\tau)}, \epsilon_{t_{n}(t), t_{n}(\tau)}^{P E}, \epsilon_{t_{n}(t), t_{n}(\tau)}^{G E} \epsilon_{t_{n}(t), t_{n}(\tau)}^{k}$ and $\epsilon_{t_{n}(t), t_{n}(\tau)}^{k, G E}$ when $n$ goes to $\infty$. We denote these limits by $\epsilon_{t, \tau}, \epsilon_{t, \tau}^{P E}, \epsilon_{t, \tau}^{G E}, \epsilon_{t, \tau}^{k}$, and $\epsilon_{t, \tau}^{k, G E}$. They represent the elasticities of output at date $t$ to a localized cumulated interest rate change $\Delta r_{\tau}$ at date $\tau$, by which we mean a change in the interest rate path $\left\{\hat{r}_{t}\right\}$ given by $\hat{r}_{t}=r+\Delta r_{\tau} \delta_{\tau}(t)$ where $\delta_{\tau}$ is the Dirac function so that $\int_{0}^{t}\left(\hat{r}_{u}-r\right) d u=0$ for $t<\tau$ and $\int_{0}^{t}\left(\hat{r}_{u}-r\right) d u=\Delta r_{\tau}$ for $t>\tau$.

We also define the continuous-time analogue $\mathcal{E}_{c t}^{k}(r(\tau-t))$ of $\mathcal{E}^{k}(R-1, \tau-t)$ :

$$
\mathcal{E}_{c t}^{k}(r(\tau-t))=\sum_{m=0}^{k-1} \frac{[r(\tau-t)]^{m}}{m !}
$$

where $\mathcal{E}_{c t}^{k}(r(\tau-t))$ is increasing in $k$ with $\mathcal{E}_{c t}^{1}(r(\tau-t))=1$ and $\lim _{k \rightarrow \infty} \mathcal{E}_{c t}^{k}(r(\tau-t))=$ $e^{r(\tau-t)}$.

Proposition 3 (Representative agent, continuous time). Consider the representative-agent model with isoelastic utility and either rational expectations or level-k thinking. For $t>\tau$ the interest rate elasticities of output are zero $\epsilon_{t, \tau}=\epsilon_{t, \tau}^{k}=0$. For $t \leq \tau$, they depend only on the horizon $\tau-t$ and are given by

$$
\begin{aligned}
\epsilon_{t, \tau}=\sigma, \quad \epsilon_{t, \tau}^{P E} & =\sigma e^{-r(\tau-t)}, \quad \epsilon_{t, \tau}^{G E}=\sigma\left[1-e^{-r(\tau-t)}\right], \\
\epsilon_{t, \tau}^{k} & =\sigma e^{-r(\tau-t)} \mathcal{E}_{c t}^{k}(r(\tau-t)) .
\end{aligned}
$$


All of our other results go through and the intuitions are identical. In particular, level- $k$ thinking features (weak) mitigation $\epsilon_{t, \tau}^{k}<\epsilon_{t, \tau}$, and monotonic convergence with $\frac{\partial \epsilon_{t, \tau}^{k}}{\partial k}>0$ and $\lim _{k \rightarrow \infty} \epsilon_{t, \tau}^{k}=1$. Compared to the discrete-time case, a useful simplification occurs for $k=1$ since now have

$$
\epsilon_{t, \tau}^{1}=\epsilon_{t, \tau}^{P E}=\sigma e^{-r(\tau-t)},
$$

so that level-1 now coincides exactly (and not just approximately) with the PE effect. This is because in continuous time, the impact of current income on current consumption vanishes, since it becomes a vanishing fraction of permanent income. As a result, the (weak) horizon effect is now given by

$$
\frac{\partial \epsilon_{t, \tau}^{1}}{\partial \tau}=-r \epsilon_{t, \tau}^{1}
$$

so that its strength is simply $r$.

\section{The Perpetual-Youth Model of Borrowing Constraints}

In this section we introduce a standard overlapping generations model of the "perpetual youth" variety a la Yaari (1965) and Blanchard (1985). As is well known, overlapping generation models can be reinterpreted as models with heterogenous agents subject to borrowing constraints (see e.g. Woodford, 1990, Kocherlakota 1992). The death event under the finite lifetime interpretation represents a binding borrowing constraint in the other interpretation. The important common property is that horizons are shortened in that consumption is only smoothed over a limited intervals of time.

We offer an explicit interpretation along these lines. The perpetual youth setup with homothetic preferences and annuities allows us to neatly isolate the impact of occasionally binding borrowing constraints while getting rid of precautionary savings. It also implies that the model aggregates linearly, and therefore, that no extra aggregate state variable capturing the wealth distribution is required to characterize the aggregate equilibrium.

We set up the model directly in continuous time for tractability. The economy is populated by infinitely-lived agents randomly hit by idiosyncratic discount factor shocks that make borrowing constraints bind according to a Poisson process. There is unit mass of ex-ante identical atomistic agents indexed by $i$ which is uniformly distributed over $[0,1]$.

We assume that per-period utility $U$ is isoelastic with a unitary intertemporal elasticity of substitution $\sigma=1$ which simplifies the analysis. We refer the reader to the appendix 
for the case $\sigma \neq 1$.

We allow for positive outside liquidity in the form of Lucas trees in unit-supply with time- $t$ value $V_{t}$ capitalizing a stream $\delta Y_{t}$ of dividends and with non-financial (labor) income given by $(1-\delta) Y_{t}$, the ownership of which at date 0 is uniformly distributed across agents. At every date, non-financial income is distributed uniformly across the population.

Agents can invest in Lucas trees and also borrow and lend in short-term risk-free bonds with the sequence of instantaneous interest rates $\left\{r_{t}\right\}$ subject to their borrowing constraints, and can also purchase actuarially fair annuities.

Individual problem. We first describe the individual problem. We proceed as in Section 3.1 to formulate the individual problem given the aggregate paths $\left\{Y_{t}, Y_{t}^{e}, r_{t}\right\}$ directly in terms of total financial wealth $a_{t}^{i}$ as long as Lucas trees satisfy the no-arbitrage conditions

$$
V_{t}=\int_{0}^{\infty} \delta Y_{t+s} e^{-\int_{0}^{s} r_{t+u} d u} d s
$$

Agents are hit by idiosyncratic Poisson shocks with intensity $\lambda$. The life of an agent $i$ is divided into "periods" by the successive realizations $n$ of his idiosyncratic Poisson process occurring at the stopping times $\tau_{n}^{i}$, with the convention $\tau_{0}^{i}=0$. The agent has a low discount factor $\beta<1$ between the different "periods" and an instantaneous discount rate $\rho$ within each "period". Importantly, the agent cannot borrow against his future non-financial or human wealth accruing in any future "period". In other words, for $\tau_{n}^{i} \leq t<\tau_{n+1}^{i}$, agent $i$ cannot borrow against any future non-financial income or human wealth accruing after $\tau_{n+1}^{i}$. We assume that the discount factor $\beta<1$ is sufficiently low that agents are up against their borrowing constraints between two "periods", so that in equilibrium, agents always choose not to bring in any financial wealth from one "period" to the next and hence that $a_{\tau_{n+1}^{i}}^{i}=0$ for all $n \geq 0$ and $i \in[0,1]$, where $a_{t}^{i}$ denotes the financial wealth of agent $i$ at time $t$. The parameter $\lambda$ can then be thought of as indexing the frequency of binding borrowing constraints.

The problem of an individual agent at date $t$ with financial wealth $a_{t}^{i}$ and who is in "period" $n_{t}$ is therefore given by

$$
\max _{\left\{\tilde{c}_{t+s}^{i}, \tilde{a}_{t+s}^{i}\right\}} \mathbb{E}_{t} \sum_{n=0}^{\infty} \beta^{n} \int_{\tau_{n_{t}+n}^{i}}^{\tau_{n_{t}+n+1}^{i}} \log \left(\tilde{c}_{t+s}^{i}\right) e^{-\rho s} d s,
$$


subject to the future expected budget constraints

$$
\frac{d \tilde{a}_{t+s}^{i}}{d s}=\left(r_{t+s}+\lambda\right) \tilde{a}_{t+s}^{i}+Y_{t+s}^{e}-\tilde{c}_{t+s}^{i} \quad \text { for } \quad \tau_{n_{t}+n}^{i} \leq t+s<\tau_{n_{t}+n+1}^{i},
$$

the initial condition

$$
\tilde{a}_{t}^{i}=a_{t}^{i}
$$

and the borrowing constraints

$$
\tilde{a}_{\tau_{n_{t}+n+1}}^{i}=0 \quad \forall n \geq 0 .
$$

The individual consumption function is the policy function for consumption at date $t$ and is given by

$$
c^{*}\left(a_{t}^{i} ;\left\{r_{t+s}\right\},\left\{Y_{t+s}^{e}\right\}\right)=(\rho+\lambda)\left[a_{t}^{i}+\int_{0}^{\infty}(1-\delta) Y_{t+s}^{e} e^{-\int_{0}^{s}\left(r_{t+u}+\lambda\right) d u} d s\right] .
$$

Note that this policy function is independent of the "period" $n$ because the idiosyncratic Poisson process is memoryless. It depends only on expected future income $\left\{Y_{t+s}^{e}\right\}$ but not on current income $Y_{t}$ because of the continuous time assumption.

The law of motion for $a_{t}^{i}$ is given by the actual (as opposed to expected) budget constraints

$$
\frac{d a_{t}^{i}}{d t}=\left(r_{t}+\lambda\right) a_{t}^{i}+Y_{t}-c^{*}\left(a_{t}^{i} ;\left\{r_{t+s}\right\},\left\{Y_{t+s}^{e}\right\}\right) \quad \text { for } \quad \tau_{n_{t}+n}^{i} \leq t+s<\tau_{n_{t}+n+1}^{i},
$$

the initial condition

$$
a_{0}^{i}=V_{t}
$$

and the borrowing constraints

$$
a_{\tau_{n}}^{i}=0 \quad \forall n \geq 1
$$

Aggregate state variable. The model also features an aggregate state variable as in Section 2.2: the wealth distribution $\Psi_{t}=\left\{a_{t}^{i}\right\}$. The law of motion for $\Psi_{t}$ is entirely determined by the laws of motion for individual financial wealth $a_{t}^{i}$. However as we shall see below, this aggregate state variable is not required to characterize the aggregate equilibrium.

Reduced-form aggregate consumption function. The reduced-form aggregate consumption function is obtained by aggregating over $i$ the individual consumption function 
$C\left(\left\{r_{t+s}\right\},\left\{Y_{t+s}^{e}\right\}\right)=\int_{0}^{1} c^{*}\left(a_{t}^{i} ;\left\{r_{t+s}\right\},\left\{Y_{t+s}^{e}\right\}\right) d i$ and imposing the asset market clearing condition $\int a_{t}^{i} d i=V_{t}$, where $V_{t}$ is given by the no-arbitrage condition (7). This yields

$$
C\left(\left\{r_{t+s}\right\},\left\{Y_{t+s}^{e}\right\}\right)=(\rho+\lambda)\left[\int_{0}^{\infty} \delta Y_{t+s}^{e} e^{-\int_{0}^{s} r_{t+u} d u} d s+\int_{0}^{\infty}(1-\delta) Y_{t+s}^{e} e^{-\int_{0}^{s}\left(r_{t+u}+\lambda\right) d u} d s\right]
$$

Just like the individual consumption function, and for the same reason, the reducedform aggregate consumption function depends only on expected future income $\left\{Y_{t+s}^{e}\right\}$ but not on current income $Y_{t}$. More importantly, the aggregate consumption function is independent of the aggregate state variable $\Psi_{t}=\left\{a_{t}^{i}\right\}$.

Remarkably, the only difference in the reduced form aggregate consumption function compared to the representative-agent model analyzed in Sections 3.2-3.3 is that future expected aggregate non-financial income $(1-\delta) Y_{t+s}^{e}$ is discounted at rate $e^{-\int_{0}^{s}\left(r_{t+u}+\lambda\right) d u}$ instead of $e^{-\int_{0}^{s} r_{t+u} d u}$. Future expected aggregate financial income $\delta Y_{t+s}^{e}$, incorporated in the value of Lucas trees $V_{t}$, is still discounter at rate $e^{-\int_{0}^{s} r_{t+u} d u}$. This is intuitive since borrowing constraints limit the ability of agents to borrow against future non-financial income but does not prevent them from selling their assets when they are borrowing constraints. ${ }^{16}$ The representative-agent model can be obtained as the limit of this model when the frequency $\lambda$ of binding borrowing constraints goes to zero.

Equilibrium characterization. For concreteness, we briefly characterize the various equilibria in the context of this particular model. Given beliefs $\left\{Y_{t}^{e}\right\}$, and given the path for interest rates $\left\{r_{t}\right\},\left\{r_{t}, Y_{t}\right\}$ is a temporary equilibrium if and only if the path for aggregate income $\left\{Y_{t}\right\}$ is given by

$$
Y_{t}=(\rho+\lambda)\left[\int_{0}^{\infty} \delta Y_{t+s}^{e} e^{-\int_{0}^{s} r_{t+u} d u} d s+\int_{0}^{\infty}(1-\delta) Y_{t+s}^{e} e^{-\int_{0}^{s}\left(r_{t+u}+\lambda\right) d u} d s\right] \quad \forall t \geq 0 .
$$

Similarly, given the path for interest rates $\left\{r_{t}\right\},\left\{r_{t}, Y_{t}\right\}$ is an REE if and only if the path for aggregate income $\left\{Y_{t}\right\}$ satisfies the fixed point

$$
Y_{t}=(\rho+\lambda)\left[\int_{0}^{\infty} \delta Y_{t+s} e^{-\int_{0}^{s} r_{t+u} d u} d s+\int_{0}^{\infty}(1-\delta) Y_{t+s} e^{-\int_{0}^{s}\left(r_{t+u}+\lambda\right) d u} d s\right] \quad \forall t \geq 0 .
$$

\footnotetext{
${ }^{16}$ Note that this requires financial assets to be liquid. Financial income (dividends) from partly illiquid assets should be discounted at a higher rate. For example, suppose that a fraction of trees can be sold while others cannot (or at a very large cost). Illiquid trees should then be treated like non-financial income. The financial income of illiquid trees should be discounted at rate $e^{-\int_{0}^{s}\left(r_{t+u}+\lambda\right) d u}$ while that of liquid trees should be discounted at rate $e^{-\int_{0}^{s} r_{t+u} d u}$. In essence, introducing illiquid trees is isomorphic to a reduction in $\delta$.
} 
Finally given an initial REE $\left\{r_{t}, Y_{t}\right\}$ and a new interest rate path $\left\{\hat{r}_{t}\right\}$, the level-k equilibria $\left\{\hat{r}_{t}, \hat{Y}_{t}^{k}\right\}$ satisfy the following recursion over $k \geq 0$ :

$$
\hat{Y}_{t}^{k}=(\rho+\lambda)\left[\int_{0}^{\infty} \delta \hat{Y}_{t+s}^{k-1} e^{-\int_{0}^{s} r_{t+u} d u} d s+\int_{0}^{\infty}(1-\delta) \hat{Y}_{t+s}^{k-1} e^{-\int_{0}^{s}\left(r_{t+u}+\lambda\right) d u} d s\right] \quad \forall t \geq 0 .
$$

with the initialization that $\hat{Y}_{t}^{0}=Y_{t}$ for all $t \geq 0$.

We now turn to the computation of the different interest rate elasticities of output around a steady state REE $\left\{R_{t}, Y_{t}\right\} Y_{t}=Y>0$ and $r_{t}=r$ for all $t \geq 0$ with

$$
1=(1-\delta) \frac{\rho+\lambda}{r+\lambda}+\delta \frac{\rho+\lambda}{r} .
$$

Later when we derive comparative statics with respects to variations in $\lambda$, we vary $\rho$ at the same time to keep the interest rate constant at $r$.

Monetary policy at different horizons under RE. We start with the RE case, where we use the selection $\lim _{t \rightarrow \infty} Y_{t}=Y$ as we perform the comparative statics underlying the computation of the interest rate elasticities of output.

Proposition 4 (Perpetual youth model of borrowing constraints, RE). Consider the perpetual youth model of borrowing constraints with logarithmic utility $\sigma=1$ and rational expectations. For $t>\tau$ the interest rate elasticities of output are zero $\epsilon_{t, \tau}=0$. For $t \leq \tau$, they depend only on the horizon $\tau-t$ and are given

$$
\epsilon_{t, \tau}=1
$$

They can be decomposed as $\epsilon_{t, \tau}=\epsilon_{t, \tau}^{P E}+\epsilon_{t, \tau}^{G E}$ into PE and GE elasticities $\epsilon_{t, \tau}^{P E}$ and $\epsilon_{t, \tau}^{G E}$. For $t>\tau$ these elasticities are zero $\epsilon_{t, \tau}^{P E}=\epsilon_{t, \tau}^{G E}=0$. For $t \leq \tau$, they are given by

$$
\begin{aligned}
\epsilon_{t, \tau}^{P E} & =(1-\delta) \frac{\rho+\lambda}{r+\lambda} e^{-(r+\lambda)(\tau-t)}+\delta \frac{\rho+\lambda}{r} e^{-r(\tau-t)} \\
\epsilon_{t, \tau}^{G E} & =(1-\delta) \frac{\rho+\lambda}{r+\lambda}\left[1-e^{-(r+\lambda)(\tau-t)}\right]+\delta \frac{\rho+\lambda}{r}\left[1-e^{-r(\tau-t)}\right] .
\end{aligned}
$$

A remarkable result in this proposition is that the interest rate elasticity of output $\epsilon_{t, \tau}$ is completely independent of the frequency $\lambda$ of binding borrowing constraints

$$
\frac{\partial \epsilon_{t, \tau}}{\partial \lambda}=0
$$

and is therefore exactly identical to its counterpart in the representative-agent model as described in Proposition 1 adapted to continuous time in Proposition 3. In other words, 
the incompleteness of markets introduced in the perpetual youth model of borrowing constraints is irrelevant for the aggregate effects of monetary policy. This is essentially a version of the incomplete markets irrelevance result of Werning (2015). Although the result also holds for any $\delta>0$, the intuition is conveyed most transparently in the case of no outside liquidity $\delta=0$ because in this case $\rho=r$ is independent of $\lambda$ (otherwise we have to vary $\rho$ so as to keep $r$ constant when we vary $\lambda$ ). The PE effect is weaker, the higher is $\lambda$, so that

$$
\frac{\partial \epsilon_{t, \tau}^{P E}}{\partial \lambda}=-(\tau-t) e^{-(r+\lambda)(\tau-t)}<0
$$

This is because for a given path of output, a higher frequency $\lambda$ of borrowing constraints leads to more discounting of future interest rate cuts, and hence to a response of consumption to a future interest rate cut in partial equilibrium. But the GE effect is stronger, the higher is $\lambda$, leading to a complete offset

$$
\frac{\partial \epsilon_{t, \tau}^{G E}}{\partial \lambda}=-\frac{\partial \epsilon_{t, \tau}^{P E}}{\partial \lambda}>0
$$

This is because the aggregate marginal propensity to consume $\rho+\lambda=r+\lambda$ increases with the frequency $\lambda$ of borrowing constraints, and hence so does the general equilibrium Keynesian multiplier. ${ }^{17}$

Monetary policy at different horizons under level- $k$. We now turn to the level- $k$ case.

Proposition 5 (Perpertual youth model of borrowing constraints, level-k). Consider the perpetual youth model of borrowing constraints with logarithmic utility $\sigma=1$ and level-k thinking. For $t>\tau$ the interest rate elasticities of output are zero $\epsilon_{t, \tau}^{k}=0$. For $t \leq \tau$, they depend only on the horizon $\tau-t$ and are given by the recursion

$$
\epsilon_{t, \tau}^{k}=\frac{\delta \frac{e^{-r(\tau-t)}}{r}+(1-\delta) \frac{e^{-(r+\lambda)(\tau-t)}}{r+\lambda}+\delta \frac{1}{r} \int_{0}^{\tau-t} \epsilon_{t+s, \tau}^{k-1} r e^{-r s} d s+(1-\delta) \frac{1}{r+\lambda} \int_{0}^{\tau-t} \epsilon_{t+s, \tau}^{k-1}(r+\lambda) e^{-(r+\lambda) s} d s}{\delta \frac{1}{r}+(1-\delta) \frac{1}{r+\lambda}},
$$

with the initialization $\epsilon_{t, \tau}^{0}=0$. This simplifies in the extreme cases of no outside liquidity $\delta=0$ and very abundant outside liquidity when $\delta$ goes to 1 :

$$
\begin{aligned}
& \epsilon_{t, \tau}^{k}=e^{-(r+\lambda)(\tau-t)} \mathcal{E}_{c t}^{k}((r+\lambda)(\tau-t)) \text { when } \delta=0, \\
& \epsilon_{t, \tau}^{k}=e^{-r(\tau-t)} \mathcal{E}_{c t}^{k}(r(\tau-t)) \text { when } \delta \rightarrow 1 .
\end{aligned}
$$

\footnotetext{
${ }^{17}$ Note that this property holds despite the existence of a countervailing effect that arises because the increase in human wealth associated with the general equilibrium increase in output is lower when $\lambda$ is higher because human wealth is more discounted.
} 
Unlike in the rational-expectations case, under level- $k$, the interest rate elasticity of output $\epsilon_{t, \tau}^{k}$ depends of the frequency $\lambda$ of binding borrowing constraints, breaking the irrelevance-of-incomplete-markets result in Werning (2015). Indeed, there are now similarities but also important differences between Proposition 5 and its counterpart in the representative-agent model as described in Proposition 2 adapted to continuous time in Proposition 3.

With incomplete markets like in the representative-agent case, level- $k$ thinking features mitigation $\epsilon_{t, \tau}^{k}<\epsilon_{t, \tau}$, and monotonic convergence with $\frac{\partial \epsilon_{t, \tau}^{k}}{\partial k}>0$ and $\lim _{k \rightarrow \infty} \epsilon_{t, \tau}^{k}=1$ . In addition, level-1 coincides exactly with the PE effect $\epsilon_{t, \tau}^{1}=\epsilon_{t, \tau}^{P E}$.

But $\epsilon_{t, \tau}^{k}$ now depends on the frequency $\lambda$ of binding borrowing constraints as long as $\delta<1$, and as a result differs from its value in the rational-expectations case, where we vary $\rho$ to keep the interest rate $r$ constant as we vary $\lambda$. For simplicity, we focus on the case with no outside liquidity $\delta=0$ where $r=\rho$, which leads to very transparent formulas. For any $k, \epsilon_{t, \tau}^{k}$ decreases with $\lambda$ so that more frequent borrowing constraints lead to stronger mitigation of the effects of monetary policy

$$
\frac{\partial \epsilon_{t, \tau}^{k}}{\partial \lambda}=-e^{-(r+\lambda)(\tau-t)} \frac{(r+\lambda)^{k-1}(\tau-t)^{k}}{(k-1) !}<0 .
$$

Moreover, for any $k, \frac{\partial \epsilon_{t, \tau}^{k}}{\partial \tau}$ decreases with $\lambda$ so that more frequent borrowing constraints lead to stronger horizon effects of monetary policy for small enough horizons

$$
\frac{\partial^{2} \epsilon_{t, \tau}^{k}}{\partial \lambda \partial \tau}=\epsilon_{t, \tau}^{k} \frac{(r+\lambda)(\tau-t)-k}{\tau-t}<0 \quad \text { for } \quad(\tau-t)<\frac{k}{r+\lambda} .
$$

These effects disappear in the rational-expectations case which obtains in the limit where $k$ goes to $\infty$. These effects also disappear when outside liquidity is very abundant in the limit where $\delta$ goes to 1 since then $\epsilon_{t, \tau}^{k}=e^{-r(\tau-t)} \mathcal{E}_{c t}^{k}(r(\tau-t))$ is independent of $\lambda$.

This can be seen most clearly in the case $k=1$ where when $\delta=0$, we get

$$
\epsilon_{t, \tau}^{1}=e^{-(r+\lambda) t}, \quad \text { and } \quad \frac{\partial \epsilon_{t, \tau}^{1}}{\partial \tau}=-(r+\lambda) \epsilon_{t, \tau}^{1}
$$

so that the strength of the mitigation and horizon effects is $r+\lambda$ instead of $r$ in the representative-agent case. As a result, the mitigation and horizon effects are plausibly much stronger than in the representative-agent case, even if the interest rate is very low. If the annual interest rate is $r=5 \%$, then the effects of monetary policy decrease at rate $5 \%$ per year with a half life of 14 years if $\lambda=0$ as in the representative-agent case, but 
decrease at rate $15 \%$ per year with a half life of 5 years if $\lambda=10 \%$; if the annual interest rate is $1 \%$ the effects of monetary policy decrease at rate $11 \%$ per year with a half life of 69 years if $\lambda=0$ as in the representative-agent case, but decrease at rate $11 \%$ per year with a half life of 6 years if $\lambda=10 \%$. In the limit of very abundant outside liquidity when $\delta$ goes to 1 instead, we have $\epsilon_{t, \tau}^{1}=e^{-r t}$ and $\frac{\partial \epsilon_{t, \tau}^{1}}{\partial \tau}=-r \epsilon_{t, \tau}^{1}$ as in the representative-agent case and independently of $\lambda$.

The results for a finite $k$ are in striking contrast to the rational-expectations benchmark, which obtains in the limit where $k$ goes to $\infty$. Level- $k$ thinking leads to a mitigation of the effects of monetary policy so that interest rate changes have less of an effect on output. Level- $k$ thinking also leads to a horizon effect of monetary policy so that interest rate changes have less of an effect on output, the further in the future they take place. The mitigation and horizon effects that arise with level- $k$ thinking are stronger, the more frequent are borrowing constraints, i.e. the higher is $\lambda$. This illustrates a profound interaction between level- $k$ thinking and incomplete markets. This interaction disappears in the limit where outside liquidity is very abundant when $\delta$ goes to 1 .

There is a simple intuition for all these results in terms of the decomposition of the effects of monetary policy into PE and GE effects. As already explained in Section 3, the PE effect features mitigation-the effect of interest rate changes is lower than the full effect under rational expectations because the latter is the sum of the GE and the PE effect. It also features horizon-for a fixed path of output, interest rate changes affect partial equilibrium consumption less, the further in the future they are. Under rational expectations, the GE effect eliminates the mitigation effect by adding to the PE effect, and also eliminates the horizon effect because the GE effect features an anti-horizon effect. With level-1 thinking, monetary policy coincides with the PE effect and features mitigation and horizon. In the rational-expectations limit when $k$ goes to $\infty$, the mitigation and horizon effects disappear. Intermediate values of $k$ interpolate smoothly and monotonically between these two extremes.

The effects of the frequency $\lambda$ of binding borrowing constraints can be understood as follows. The horizon and mitigation effects of the PE effect are stronger, the higher is $\lambda$ because of higher discounting of non-financial (human) wealth. Under rational expectations, the GE effect offsets this dependence on $\lambda$ because the aggregate marginal propensity to consume $\rho+\lambda$ and hence the Keynesian multiplier increase with $\lambda$. At level-1, monetary policy coincides with the PE effect and the horizon and mitigation features are stronger, the higher is $\lambda$. In the rational-expectations limit where $k$ goes to $\infty$, the dependence of the mitigation and horizon effects on $\lambda$ disappears. Intermediate values of $k$ interpolate smoothly and monotonically between these two extremes. This also explains 
why the interaction between bounded rationality and incomplete markets disappears in the limit where outside liquidity is very abundant when $\delta$ goes to 1 , since it is only nonfinancial (human) wealth which is more discounted when borrowing constraints bind more often, but not the dividends promised by the Lucas trees.

\section{The Bewley-Aiyagari-Huggett Model of Borrowing Con- straints and Precautionary Savings}

In this section, we consider a standard Bewley-Aiyagari-Huggett model of incomplete markets. This model features not only occasionally binding borrowing constraints like the perpetual youth model of borrowing constraints developed in Section 4 but also precautionary savings. As a result, individual consumption functions are no longer linear but are instead concave, linear aggregation does not obtain, and the wealth distribution becomes a relevant aggregate state variable.

There is a unit mass of infinitely-lived agents indexed by $i$ distributed uniformly over $[0,1]$. Time is discrete with a period taken to be a quarter. Agents have logarithmic utility $\sigma=1$ and discount factor $\beta$.

Agents face idiosyncratic non-financial income risk $y_{t}^{i}(1-\delta) Y_{t}$. There is a unit supply of Lucas trees capitalizing the flow of dividends $\delta Y_{t}$. The idiosyncratic income process is $\log \left(y_{t}^{i}\right)=\rho_{\epsilon} \log \left(y_{t-1}^{i}\right)+\epsilon_{t}^{i}$, where $\epsilon_{t}^{i}$ is i.i.d. over time, independent across agents and follows a normal distribution with variance $\sigma_{\epsilon}^{2}$ and mean $\mathbb{E}\left[\epsilon_{t}^{i}\right]=-\sigma_{\epsilon}^{2} / 2$ so that $\int e^{\epsilon_{t}^{i}} d i=1$.

Agents can borrow and lend subject to borrowing constraints. We assume that the borrowing contracts have the same form as the Lucas trees. We also assume that the borrowing constraints take a simple form, namely that agents cannot have a negative position asset position. These choices ensure that under rational expectations, the irrelevance result of Werning (2015) holds, and the interest rate elasticity of output coincides with that of a complete-markets or representative agent model $\epsilon_{t, \tau}=1$.

Individual problem. We first describe the individual problem. We proceed as in Section 3.1 to formulate the individual problem given the aggregate paths $\left\{Y_{t}, Y_{t}^{e}, R_{t}\right\}$ directly in terms of total financial wealth $a_{t}^{i}$ as long as Lucas trees satisfy the no-arbitrage conditions (6).

The problem on an at date $t$ with financial wealth $a_{t}^{i}$ is 


$$
\max _{\left\{\hat{c}_{t+s}^{i}, \tilde{a}_{t+1+s}^{i}\right\}} \mathbb{E}_{t} \sum_{s=0}^{\infty} \beta^{s} \log \left(\tilde{c}_{t+s}^{i}\right) d s,
$$

subject to the current actual budget constraint

$$
\tilde{c}_{t}^{i}=(1-\delta) y_{t}^{i} Y_{t}+a_{t}^{i}-\frac{\tilde{a}_{t+1}^{i}}{R_{t}}
$$

the future expected budget constraints

$$
\tilde{c}_{t+1+s}^{i}=(1-\delta) y_{t+1+s}^{i} Y_{t+1+s}^{e}+\tilde{a}_{t+1+s}^{i}-\frac{\tilde{a}_{t+2+s}^{i}}{R_{t+1+s}} \quad \forall s \geq 0,
$$

and the borrowing constraints

$$
\tilde{a}_{t+1+s}^{i} \geq 0 \quad \forall s \geq 0
$$

The policy function for consumption at date $t$ is the individual consumption function and is given by $c^{*}\left(a_{t}^{i}, y_{t}^{i} ;\left\{R_{t+s}\right\}, Y_{t},\left\{Y_{t+s}^{e}\right\}\right)$. The law of motion for $a_{t}^{i}$ is given by the actual (as opposed to expected) budget constraint $a_{t+1}^{i}=R_{t}\left[(1-\delta) y_{t}^{i} Y_{t}+a_{t}^{i}-c^{*}\left(a_{t}^{i}, y_{t}^{i} ;\left\{R_{t+s}\right\}, Y_{t},\left\{Y_{t+s}^{e}\right\}\right)\right]$.

Aggregate state variable. The model also features an aggregate state variable as in Section 2.2: the joint distribution of wealth and income shocks $\Psi_{t}=\left\{a_{t}^{i}, y_{t}^{i}\right\}$. The law of motion for $\Psi_{t}$ is entirely determined by the laws of motion for individual financial wealth and income shocks given an initial condition $\Psi_{0}$ with $\int a_{0} d \Psi\left(a_{0}, y_{0}\right)=V_{0}$, where $V_{0}$ is given by the no-arbitrage condition (6) and $\int y_{0} d \Psi\left(a_{0}, y_{0}\right)=1$. In contrast to the perpetual youth model of borrowing constraints developed in Section 4 , this aggregate state variable is required to characterize the aggregate equilibrium.

Reduced-form aggregate consumption function. The reduced-form aggregate consumption function is obtained by aggregating over $i$ the individual consumption function

$$
C\left(\left\{R_{t+s}\right\}, Y_{t},\left\{Y_{t+s}^{e}\right\}, \Psi_{t}\right)=\int_{0}^{1} c^{*}\left(a_{t}, y_{t} ;\left\{R_{t+s}\right\}, Y_{t},\left\{Y_{t+s}^{e}\right\}\right) d \Psi_{t}\left(a_{t}, y_{t}\right) .
$$

Temporary equilibria, RE equilibria, and level- $k$ equilibria are then defined exactly as in the general reduced form model described in Section 2. 
Monetary policy at different horizons. This model cannot be solved analytically, and so we rely on simulations instead. We consider a steady state $\{Y, R, \Psi\}$ of the model with a $2 \%$ annual interest rate and a corresponding quarterly interest rate of $R=1.005$. We take $\rho_{\epsilon}=0.966$, and $\sigma_{\epsilon}^{2}=0.017$ for the idiosyncratic income process as in McKay et al. (2016) and Guerrieri and Lorenzoni (2015). For our baseline economy, we take $\frac{V}{Y}=1.44$ for the fraction of outside liquidity to output, exactly as in McKay et al. (2016). ${ }^{18}$ The values of $\beta=0.988$ and $\delta=0.035$ are calibrated to deliver these values of $R$ and $\frac{V}{Y}$. The fraction of borrowing-constrained agents in the steady state is then $14.7 \%$.

Figure 1 depicts the proportional output response of the economy to a $1 \%$ interest rate cut at different horizons, or in other words, the interest rate elasticity of output $\epsilon_{0, \tau}^{k}$ at different horizons $\tau$, for different values of $k$, comparing the incomplete-markets baseline economy with the complete-markets or representative-agent version of the same economy.

The top panel illustrates the strong mitigation and horizon effects brought about by the interaction of incomplete markets and bounded rationality, by comparing the economy with $k=1$ and incomplete markets, the economy with $k=1$ and complete markets, and the economy with rational expectations which obtains in the limit when $k$ goes to $\infty$ where the degree of market incompleteness becomes irrelevant by construction. It also shows how these mitigation and horizon effects dissipate as we increase the level of reasoning $k$, moving towards rational expectations. In the present simulation, the convergence to rational expectations is quite fast, resulting in outcomes that are close to rational expectations for values $k \geq 2$. However, the simulation is only illustrative and fast convergence is not a general property. In addition, very low levels of $k$, including $k=1$, are perhaps realistic as descriptions of household behavior when confronted with unusual monetary policy announcements. ${ }^{19}$

Figure 2 illustrates how these effects change as we move away from the baseline economy by varying the discount factor $\beta$ and the amount of liquidity $\delta$ while keeping the steady-state annual interest rate constant at $2 \%$. These different calibrations can be understood as representing different degrees of market incompleteness since they lead to different values for the fraction of borrowing-constrained agents in the steady state and for the aggregate marginal propensity to consume. The model approximates the completemarkets model in the limit where this fraction goes to zero.

\footnotetext{
${ }^{18}$ This value for the fraction of outside liquidity to output $\frac{V}{Y}=1.44$ is meant to capture the value of liquid (as opposed to illiquid) wealth in the data.

${ }^{19}$ We are suggesting that level- $k$ thinking may be higher in other contexts. For example, in financial markets, deeply invested traders may undertake much higher rounds of thinking. In the present model it is consumption decisions by households that matter, making low levels of $k$ more relevant.
} 
Once again the figure powerfully illustrates the strong interaction of incomplete markets and bounded rationality: For a given finite value of $k$, the mitigation and horizon effects are much stronger when markets are more incomplete in the sense that the steadystate fraction of borrowing-constrained agents is higher; furthermore, the convergence to rational expectations is slower when markets are more incomplete.

Overall, in this calibrated Bewley-Aiyagari-Huggett economy with occasionally borrowing constraints and precautionary savings, there are powerful interactions between bounded rationality and incomplete markets. This reinforces the analytical results that we obtained in the perpetual youth model of borrowing constraints developed in Section 4 which features borrowing constraints but no precautionary savings.

\section{Sticky Prices and Inflation}

So far, we have abstracted from inflation by assuming that prices are fully rigid, or equivalently by focusing on the response of the economy to changes in the path of real interest rates. In this section, we study the role of inflation by departing from the assumption of fully rigid prices. We modify the model of Section 5 to incorporate monopolistic competition and staggered time-dependent pricing a la Calvo, as well as explicit labor supply and labor demand decisions. To do so, we assume that a perfectly competitive sector produces a final good by combining different varieties of intermediate goods produced by monopolistic firms facing Calvo frictions in price adjustment. We maintain a specification such that the irrelevance result of Werning (2015) holds so that under rational expectations, the responses of output and inflation to a monetary policy shock are independent of the incompleteness of markets.

Monetary policy. With sticky but imperfectly rigid prices, specifying a path for nominal interest rates still leads to a unique level- $k$ equilibrium for any value of $k$, but is no longer sufficient to ensure the convergence of the sequence of level- $k$ equilibria to a rationalexpectations equilibrium when $k$ goes to $\infty$. To obtain this property, we must consider paths of interest rate rules $R_{t}\left(\Pi_{t}\right)$ specifying nominal interest rates as a function of the inflation rate $\Pi_{t}=P_{t} / P_{t-1}$ of final goods prices (inflation for short). In what follows we often write simply write $\left\{R_{t}\right\}$ to denote the path of interest rate rules.

It is important to realize that this interest rate rule plays a very different role in level-k equilibria compared to its standard role in rational expectations equilibria. In rational expectations equilibria, sufficiently reactive interest rate rules are required to ensure the local determinacy of the equilibrium by ensuring that alternative candidate equilibria 
feature explosive dynamics and hence do not remain in the vicinity of the equilibrium because of the commitment to the rule by the monetary authority. Essentially, what matters is that the off equilibrium commitment of the central bank. In contrast, in level-k equilibria, there is a unique global equilibrium for any $k$. The interest rate rule results in an endogenously different nominal interest rate path for different values of $k$. If the interest rate rule is responsive enough, then the equilibrium converges to a rational expectations equilibrium when $k$ goes to infinity. What matters is the interest rate path in equilibrium for different values of $k$ and not any off equilibrium commitment on the part of the central bank.

Aggregate variables and beliefs. These modifications change the relevant aggregate variables. In particular, we now need to track not only the path of nominal interest rates $\left\{R_{t}\right\}$ and the paths of output $\left\{Y_{t}\right\}$ and beliefs about output $\left\{Y_{t}^{e}\right\}$, but also the paths of aggregate real profits $\left\{X_{t}\right\}$ and beliefs about profits $\left\{X_{t}^{e}\right\}$, the paths of wages $\left\{W_{t}\right\}$ and beliefs about wages $\left\{W_{t}^{e}\right\}$, the paths of prices of final goods $\left\{P_{t}\right\}$ and beliefs about prices of final goods $\left\{P_{t}^{e}\right\}$, as well as the paths of prices of intermediate goods $\left\{\hat{P}_{t}\right\}$ and beliefs about these prices $\left\{\hat{P}_{t}^{e}\right\}$. We define $\Omega_{t}=\left(Y_{t}, X_{t}, W_{t}, P_{t}, \hat{P}_{t}\right)$, and $\Omega_{t}^{e}=\left(Y_{t}^{e}, X_{t}^{e}, W_{t}^{e}, P_{t}^{e}, \hat{P}_{t}^{e}\right)$.

We assume that at every date $t$, beliefs about future wages, prices of final goods, and prices of intermediate goods ate date $t+s$ are scaled by $P_{t} / P_{t}^{e}$ so that they are given by $W_{t+s}^{e}\left(P_{t} / P_{t}^{e}\right), P_{t+s}^{e}\left(P_{t} / P_{t}^{e}\right)$, and $\hat{P}_{t+s}^{e}\left(P_{t} / P_{t}^{e}\right)$. This scaling allows the agents to incorporate the accumulated surprise inflation differential $P_{t} / P_{t}^{e}$ that has already been realized but leaves unchanged beliefs about future relative prices $W_{t+s}^{e} / P_{t+s}^{e}$ and wages $\hat{P}_{t+s}^{e} / P_{t+s}^{e}$ as well as beliefs about future inflation $\Pi_{t+s}^{e}$.

Technology. Final output is produced from intermediates by competitive firms indexed by $h \in[0,1]$ according to $y_{t}^{h}=\left[\left(\int \hat{y}_{t}^{h j \frac{\theta-1}{\theta}}\right)^{\frac{\theta}{\theta-1}}\right]^{1-\delta}$ where $\delta$ is a measure of decreasing returns to scale. Decreasing returns to scale can be thought as arising from an underlying constant returns production function featuring capital and intermediate goods with strong frictions to the adjustment of capital, a standard assumption in the New Keynesian literature. The different varieties of intermediates are produced from effective labor by monopolistic firms indexed by $j \in[0,1]$ according to $\hat{y}_{t}^{j}=n_{t}^{j}$.

Individual firm price setting. The monopolistic firms producing the different varieties of intermediate goods are subject to a price setting friction a la Calvo. They only get a chance to change their price with probability $1-\lambda$ at every date, and these opportunities are independent across firms. A firm that gets a chance to change its price at date $t-1$ 
can change its price from date $t$ onwards, and then chooses so set it to the following reset price

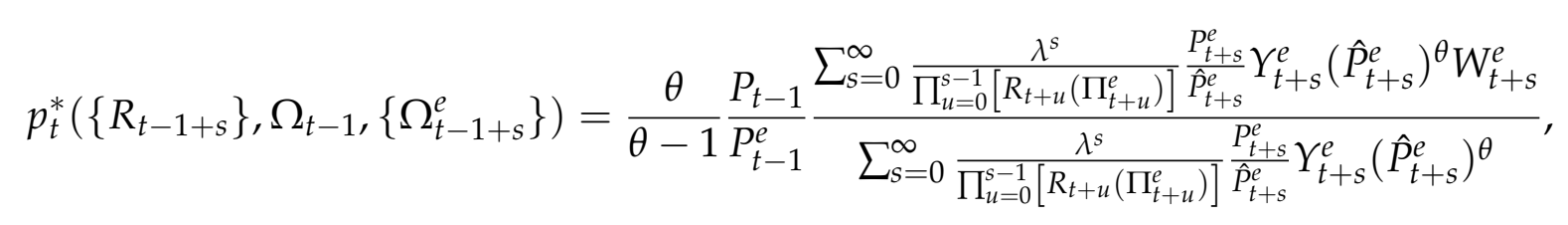

where $\theta /(\theta-1)>1$ is the desired markup and $\hat{P}_{t}=\left[\int\left(\hat{p}_{t}^{j}\right)^{1-\theta} d j\right]^{1 /(1-\theta)}$ is the price index for intermediate goods.

Profits and Lucas trees. Real aggregate profits from the monopolistic intermediate good sector are given by $X_{t}=(1-\delta) Y_{t}-\frac{W_{t}}{P_{t}} N_{t}$, where $N_{t}=\int n_{t}^{j} d j$ is effective aggregate labor. They are directly distributed to households in every period. The real aggregate profits $\delta Y_{t}$ of the competitive sector can be thought of as the rental income of capital. They are capitalized by Lucas trees, the pricing of which is given by no arbitrage

$$
\begin{aligned}
V_{t} & =\delta Y_{t}+\frac{\Pi_{t+1}^{e}}{R_{t}\left(\Pi_{t}\right)} V_{t+1}^{e} \quad \forall t \geq 0, \\
V_{t}^{e} & =\delta Y_{t}^{e}+\sum_{s=0}^{\infty} \prod_{u=0}^{s}\left[\frac{\Pi_{t+1+u}^{e}}{R_{t+u}\left(\Pi_{t+u}^{e}\right)}\right] \delta Y_{t+1+s}^{e} \quad \forall t \geq 0 .
\end{aligned}
$$

Individual agent problem. We first describe the individual problem. The problem at date $t$ with real financial wealth $a_{t}^{i}$

$$
\max _{\left\{\tilde{c}_{t+s}^{i}, \tilde{n}_{t+s}^{i}, \tilde{a}_{t+1+s}^{i}\right\}} \mathbb{E}_{t} \sum_{s=0}^{\infty} \beta^{s}\left[\log \left(\tilde{c}_{t+s}^{i}\right)-\frac{\left(\tilde{n}_{t}^{i}\right)^{1+\gamma}}{1+\gamma}\right]
$$

subject to the current actual budget constraint

$$
\tilde{c}_{t}^{i}=\frac{W_{t}}{P_{t}} z_{t}^{i} \tilde{n}_{t}^{i}+\alpha_{t}^{i} X_{t}+a_{t}^{i}-\frac{\Pi_{t+1}^{e}}{R_{t}\left(\Pi_{t}\right)} \tilde{a}_{t+1}^{i}
$$

the future expected budget constraints

$$
\tilde{c}_{t+1+s}^{i}=\frac{W_{t}^{e}}{P_{t}^{e}} z_{t+1+s}^{i} \tilde{n}_{t+1+s}^{i}+\alpha_{t+1+s}^{i} X_{t+1+s}^{e}+\tilde{a}_{t+1+s}^{i}-\frac{\Pi_{t+2+s}^{e}}{R_{t+1+s}\left(\Pi_{t+1+s}^{e}\right)} \tilde{a}_{t+2+s}^{i} \quad \forall s \geq 0,
$$

and the borrowing constraints

$$
\tilde{a}_{t+1+s} \geq 0 \quad \forall s \geq 0,
$$


where $z_{t}^{i}$ is an idiosyncratic productivity shock and $z_{t}^{i} \tilde{n}_{t}^{i}$ is effective labor. We assume that this shock follows the process $\log \left(z_{t}^{i}\right)=\rho_{\epsilon} \log \left(z_{t-1}^{i}\right)+\epsilon_{t}^{i}$ where $\epsilon_{t}^{i}$ is i.i.d. over time, independent across agents, and follows a normal distribution with variance $\sigma_{\epsilon}^{2}$ and mean $\mathbb{E}\left[\epsilon_{t}^{i}\right]=-\sigma_{\epsilon}^{2} / 2$.

We assume that the share $\alpha_{t}^{i}$ of aggregate real profits $X_{t}$ from the monopolistic intermediate goods sector received by any given agent is proportional to its equilibrium labor income $z_{t}^{i} n_{t}^{i}$. This means that profits are rebated lump sum so that agents take the profits accruing to them as given when they make their labor supply decisions since deviations from equilibrium leave $\alpha_{t}^{i}$ unchanged. As in Section 5, we assume that the borrowing contracts have the same form as the Lucas trees, and that agents cannot borrow. Taken together, these choices ensure that under rational expectations, the irrelevance result of Werning (2015) holds, and the interest rate elasticity of output and inflation coincide with those of a complete-markets or representative-agent model.

We denote the policy function for consumption by $c^{*}\left(a_{t}^{i}, z_{t}^{i} ;\left\{R_{t+s}\right\}, \Omega_{t},\left\{\Omega_{t+s}^{e}\right\}\right)$ and the policy function for labor by $n^{*}\left(a_{t}^{i}, z_{t}^{i} ;\left\{R_{t+s}\right\}, \Omega_{t},\left\{\Omega_{t+s}^{e}\right\}\right)$. As in Section 5 , the law of motion for $a_{t}^{i}$ is given by the actual (as opposed to expected) budget constraints.

Temporary, RE, and level-k equilibria. We denote by $\Psi_{t}=\left\{a_{t}^{i}, z_{t}^{i}\right\}$ the joint distribution of wealth and productivity shocks. The law of motion for $\Psi_{t}$ is entirely determined by the laws of motion for individual financial wealth and income shocks given an initial condition $\Psi_{0}$ with $\int z_{0} d \Psi\left(a_{0}, z_{0}\right)=1$ and $\int a_{0} d \Psi\left(a_{0}, z_{0}\right)=V_{0}$, where $V_{0}$ is given by the no-arbitrage conditions (8).

Temporary equilibria, RE equilibria, and level- $k$ equilibria are defined in a similar way as in the the general reduced form model described in Section 2. The main differences are that in each of these constructions, we must ensure not only that the goods market clears

$$
Y_{t}=\int_{0}^{1} c^{*}\left(a_{t}, z_{t} ;\left\{R_{t+s}\right\}, \Omega_{t},\left\{\Omega_{t+s}^{e}\right\}\right) d \Psi_{t}\left(a_{t}, z_{t}\right),
$$

but also that the labor market clears

$$
N_{t}=\int_{0}^{1} z_{t} n^{*}\left(a_{t}, z_{t} ;\left\{R_{t+s}\right\}, \Omega_{t},\left\{\Omega_{t+s}^{e}\right\}\right) d \Psi_{t}\left(a_{t}, z_{t}\right) .
$$

We must solve not only for aggregate output $Y_{t}=\int y_{t}^{h} d h$ but also for aggregate effective labor $N_{t}=\int n_{t}^{j} d j$, the wage $W_{t}$, the price of final goods $P_{t}$, and the price of intermediate goods $\hat{P}_{t}$. Because it aggregates the prices of intermediate goods producers, the price 
index for intermediate goods must follow the difference equation

$$
\hat{P}_{t}=\left[(1-\lambda)\left(p_{t}^{*}\left(\left\{R_{t-1+s}\right\}, \Omega_{t-1},\left\{\Omega_{t-1+s}^{e}\right\}\right)\right)^{1-\theta}+\lambda\left(\hat{P}_{t-1}\right)^{1-\theta}\right]^{\frac{1}{1-\theta}},
$$

with initial condition $\hat{P}_{0}=\hat{P}$. In addition, because of the optimality condition of final goods producers, we must have

$$
P_{t}=\frac{(1-\delta) \hat{P}_{t} Y_{t}}{\left(Y_{t}\right)^{\frac{1}{1-\delta}}}
$$

and

$$
N_{t}=\Delta_{t}\left(Y_{t}\right)^{\frac{1}{1-\delta}}
$$

where $\Delta_{t}$ is an index of price dispersion which satisfies the difference equation

$$
\Delta_{t}=\lambda \Pi_{t}^{\theta} \Delta_{t-1}+(1-\lambda)\left[\frac{1-\lambda \Pi_{t}^{\theta-1}}{1-\lambda}\right]^{\frac{\theta}{\theta-1}},
$$

with initial condition $\Delta_{0}=0$, which encapsulates the efficiency costs of misallocation arising from inflation.

The changes required to handle these differences involve the definition of a reducedform aggregate consumption function and of a reduced-form aggregate effective labor supply function along the lines of the above equations. They also involve the definition of a reduced-form aggregate price of intermediate goods function, of a reduced-form aggregate price of final goods function, and of a reduced-form aggregate wage function, along the lines of the above equations. The necessary steps are somewhat tedious but conceptually straightforward and so we omit them in the interest of space.

Effects of monetary policy at different horizons. To compute the effects of monetary policy at different horizons around a steady state with no inflation $\Pi=1$ and with nominal interest rate $R$, we consider the following perturbations of monetary policy indexed by $\Delta R_{\tau}$ with fixed interest rates up to $\tau$ and reactive enough rules after $\tau: R_{t}\left(\Pi_{t}\right)=R$ for $t<\tau ; R_{\tau}\left(\Pi_{t}\right)=R+\Delta R_{\tau}$; and $R_{t}\left(\Pi_{t}\right)=R \Pi_{t}^{\phi}$ for $t>\tau$. We then compute $\epsilon_{t, \tau}=\lim _{\Delta R_{\tau} \rightarrow 0}-(R / Y)\left(\Delta Y_{t} / \Delta R_{\tau}\right)$ and $\epsilon_{t, \tau}^{\Pi}=\lim _{\Delta R_{\tau} \rightarrow 0}-(R / \Pi)\left(\Delta \Pi_{t} / \Delta R_{\tau}\right)$.

The model cannot be solved analytically, and so we rely on simulations. We consider the same parameter values for $R, \rho_{\epsilon}, \sigma_{\epsilon}, \delta$, and $\beta$ as in Section 5. In addition we set $\gamma=2$ to match a Frisch elasticity of labor supply of 0.5 . We set $\theta=6$ to generate a desired markup of 1.2 and $\lambda=0.85$ which implies an average price duration of about 6 quarters 
as in Christiano et al. (2011). Finally we pick the coefficient in the interest rate rule to be $\phi=1.5$.

Figure 3 depicts the proportional output and inflation responses of the economy to a $1 \%$ interest rate cut at different horizons, or in other words, the interest rate elasticity of output $\epsilon_{0, \tau}^{k}$ and inflation $\epsilon_{0, \tau}^{\Pi, k}$ at different horizons $\tau$, for the baseline incomplete-markets economy and for the complete-markets or representative-agent version of the same economy, under level- $k$ bounded rationality for different values of $k$.

Comparing Figures 1 and 3, we verify numerically the analytical result that that for $k=1$, the response of output is identical when prices are rigid and when they are sticky, simply because at this level of reasoning, agents do not expect any inflation even if prices are sticky. It features mitigation and horizon effects. With sticky prices, the response of inflation also features mitigation and horizon effects. These effects are stronger for the incomplete-markets economy than for the complete-markets economy.

As $k$ increases, the responses of output and inflation converge monotonically to their rational-expectations counterparts. In the rational-expectations limit when $k$ goes to $\infty$, by construction, the responses of output and inflation become the same in the incompletemarkets economy and in the complete-markets economy in our model. Comparing low values of $k$ and especially $k=1$ with high values of $k$ therefore demonstrates that the complementarity between incomplete markets and bounded rationality that we uncovered in the case with rigid prices considered in Section 5 is robust to the introduction of inflation.

For high enough values of $k$, these responses acquire anti-horizon effects in the sense that the response of current output and inflation increase with the horizon of monetary policy. This is unlike the case with rigid prices considered in Section 5 where the rationalexpectations equilibrium features no horizon effect. These anti-horizon effects arise because of a feedback loop between output and inflation whereby higher output now and in the future up until the horizon of monetary policy generates higher inflation now and in the future, which reduces real interest rates and further increases output now and in the future, etc. The higher the level of reasoning $k$, the more rounds in the feedback loop, and the stronger its effects. And for a given $k$, the longer the horizon of monetary policy, the longer the time horizon over which this feedback loop plays out, and the stronger its effects.

Figure 4 illustrates how these effects change as we move away from the baseline economy by varying the discount factor $\beta$ and amount of liquidity $\delta$ while keeping the steadystate annual interest rate constant at $2 \%$. These different calibrations lead to different values for the fraction of borrowing-constrained agents in the steady state and for the 
aggregate marginal propensity to consume.

Once again the figure powerfully illustrates the strong interaction of incomplete markets and bounded rationality: For a given finite value of $k$, the mitigation and horizon effects are much stronger when the steady-state fraction of borrowing-constrained agents is higher; furthermore, the convergence to rational expectations is also slower. In fact, comparing Figures 2 and 4 for intermediate values of $k$ shows that this complementarity is amplified when moving from rigid to sticky prices. ${ }^{20}$

Overall, incorporating sticky prices and inflation worsens the "forward guidance puzzle" under rational expectations: The rational-expectations equilibrium features anti-horizon effects so that the effects of monetary policy on output and inflation strongly increase with the horizon of monetary policy. Incomplete markets alone does not change these properties since the aggregate properties of our model are invariant to the degree of market incompleteness under rational expectations. Level- $k$ bounded rationality alone mitigates and for low values of $k$ reverses these effects. But even for $k=1$, the horizon effects remain very weak, exactly as in the case of rigid prices considered in Section 5. Level- $k$ bounded rationality and incomplete markets together generate powerful horizon effects, exactly as in the case of rigid prices considered in Section 5. The complementarity between incomplete markets and bounded rationality that we identified in the case of rigid prices remains and is even strengthened with sticky prices.

\section{Conclusion}

We have demonstrated a strong interaction between two forms of frictions, bounded rationality and incomplete markets. In economies with nominal rigidities, this interaction has important implications for the transmission of monetary policy, by mitigating its effects, the more so, the further in the future that monetary policy change takes place. This offers a possible rationalization of the so-called "forward guidance puzzle". We conjecture that these conclusions generalize to other shocks and policies. We pursue these directions in ongoing work.

\footnotetext{
${ }^{20}$ There is another effect at play in this model with sticky prices that is absent in the model where all prices are rigid. Under our formulation with sticky prices for intermediate goods and flexible prices for final goods which combine intermediate goods with capital, increasing the share $\delta$ of capital in final goods production essentially reduces the share of prices that are sticky, and hence makes the prices of final goods more flexible, which amplifies the feedback loop between output and inflation and hence the effects of monetary policy. We are currently working on a different model which eliminates this effect by specifying that intermediate goods are produced from capital and labor and have sticky prices, and that final goods are produced directly from intermediates and have flexible prices.
} 


\section{References}

Angeletos, Marios and Chen Lian, "Forward Guidance without Common Knowledge," MIT working paper, MIT 2017.

Arad, Ayala and Ariel Rubinstein, "The 11-20 Money Request Game: Evaluating the Upper Bound of k-Level Reasoning," American Economic Review, 2012, 102 (5), 35613573.

Auclert, Adrien, “Monetary Policy and the Redistribution Channel," May 2017.

Blanchard, Olivier J, "Debt, Deficits, and Finite Horizons," Journal of Political Economy, April 1985, 93 (2), 223-247.

Caballero, Ricardo J. and Emmanuel Farhi, "The safety trap," The Review of Economic Studies, 2017.

Camerer, Colin, Teck-Hua Hong, and Juin-Kuan Chong, "A Cognitive Hierarchy Model of Games," Quarterly Journal of Economics, 2004, 119, 861-898.

Christiano, Lawrence, Martin Eichenbaum, and Sergio Rebelo, "When Is the Government Spending Multiplier Large?," Journal of Political Economy, 2011, 119 (1), 78-121.

Crawford, Vincent P., Miguel A. Costa-Gomes, and Nagore Iriberri, "Structural Models of Nonequilibrium Strategic Thinking: Theory, Evidence, and Applications," Journal of Economic Literature, March 2013, 51 (1), 5-62.

Del Negro, Marco, Marc Giannoni, and Christina Patterson, "The forward guidance puzzle," Staff Reports 574, Federal Reserve Bank of New York April 2015.

Eggertsson, Gauti B. and Paul Krugman, "Debt, Deleveraging, and the Liquidity Trap: A Fisher-Minsky-Koo Approach," The Quarterly Journal of Economics, 2012, 127 (3), 14691513.

Evans, George W. and Gary Ramey, "Expectation Calculation and Macroeconomic Dynamics," American Economic Review, 1992, 82, 207-224.

_ and _ , "Expectation Calculation, Hyperinflation, and Currency Collapse," in By H. Dixon and N. Rankin, eds., The New Macroeconomics: Imperfect Markets and Policy Effectiveness, Cambridge University Press, 1995. 
_ and _ , "Calculation, Adaptation, and Rational Expectations," Marcoeconomic Dynamics, 1998, 2, 156-182.

Fair, Ray and John Taylor, "Solutions and Maximum Likelihood Estimation of Dynamic Nonlinear Rational Expectations Models," Econometrica, 1983, 51, 1169-1189.

Farhi, Emmanuel and Ivan Werning, "A Theory of Macroprudential Policies in the Presence of Nominal Rigidities," Econometrica, 09 2016, 84, 1645-1704.

- and Iván Werning, "Fiscal Multipliers: Liquidity Traps and Currency Unions," Handbook of Macroeconomics, 11 2016, 2B, 2417-2492.

_ and Ivan Werning, "Fiscal Unions," American Economic Review, 2017.

Gabaix, Xavier, "A Behavioral New Keynesian Model," Harvard working paper, Harvard 2017.

Gali, Jordi, J. David Lopez-Salido, and Javier Valles, "Understanding the Effects of Government Spending on Consumption," Journal of the European Economic Association, 03 2007,5 (1), 227-270.

García-Schmidt, Mariana and Michael Woodford, "Are Low Interest Rates Deflationary? A Paradox of Perfect-Foresight Analysis," Working Paper 21614, National Bureau of Economic Research October 2015.

Grandmont, Jean-Michel, “Temporary General Equilibrium Theory,” Econometrica, April 1977,45 (3), 535-72.

Guerrieri, Veronica and Guido Lorenzoni, "Credit Crises, Precautionary Savings, and the Liquidity Trap," Working Paper 17583, National Bureau of Economic Research November 2015.

Guesnerie, Roger, "An Exploration of the Eductive Justifications of the Rational Expectations Hypothesis," American Economic Review, 1992, 82, 1254-1278.

Hicks, J. R., Value and Capital, Oxford University Press, 1939.

Jean-Michel, Grandmont, in By Grandmont Jean-Michel, ed., Temporary Equilibrium: Selected Readings, New York: Academic, 1978.

Kaplan, Greg, Benjamin Moll, and Giovanni L. Violante, "Monetary Policy According to HANK," NBER Working Papers 21897, National Bureau of Economic Research, Inc January 2016. 
Kaplan, Greg Warren and Giovanni Luca Violante, "A Model of the Consumption Response to Fiscal Stimulus Payments," Econometrica, July 2014, 82 (4), 1199-1239.

Kekre, Rohan, “Unemployment Insurance in Macroeconomic Stabilization,” 2016 Meeting Papers 1184, Society for Economic Dynamics 2016.

Kocherlakota, Narayana R., "Bubbles and constraints on debt accumulation," Journal of Economic Theory, 1992, 57 (1), 245-256.

Lindahl, E., Theory of Money and Capital, Allen and Unwin, 1939.

Mankiw, N. Gregory and Ricardo Reis, "Sticky Information versus Sticky Prices: A Proposal to Replace the New Keynesian Phillips Curve," The Quarterly Journal of Economics, 2002, 117 (4), 1295-1328.

McKay, Alisdair, Emi Nakamura, and Jón Steinsson, "The Power of Forward Guidance Revisited," American Economic Review, October 2016, 106 (10), 3133-3158.

Nagel, Rosemarie, "Unraveling in Guessing Games: An Experimental Study," American Economic Review, December 1995, 85 (5), 1313-26.

O., Stahl Dale and Wilson Paul W., “On Players' Models of Other Players: Theory and Experimental Evidence," Games and Economic Behavior, July 1995, 10 (1), 218-254.

Oh, Hyunseung and Ricardo Reis, "Targeted transfers and the fiscal response to the great recession," Journal of Monetary Economics, 2012, 59 (S), S50-S64.

Ravn, Morten O. and Vincent Sterk, "Macroeconomic Fluctuations with HANK \& SAM: An Analytical Approach," Discussion Papers 1633, Centre for Macroeconomics (CFM) October 2016.

Stahl, Dale II and Paul W. Wilson, "Experimental evidence on players' models of other players," Journal of Economic Behavior E Organization, December 1994, 25 (3), 309-327.

Sterk, Vincent and Silvana Tenreyro, "The Transmission of Monetary Policy Operations through Redistributions and Durable Purchases," CEP Discussion Papers dp1249, Centre for Economic Performance, LSE December 2013.

Werning, Iván, “Incomplete Markets and Aggregate Demand," Working Paper 21448, National Bureau of Economic Research August 2015.

Wiederholt, Mirko, "Empirical Properties of Inflation Expectations and the Zero Lower Bound," Goethe University working paper, Goethe University 2016. 
Woodford, Michael, "Public Debt as Private Liquidity," American Economic Review, May 1990,80 (2), 382-88.

_, "Macroeconomic Analysis Without the Rational Expectations Hypothesis," Annual Review of Economics, 2013, 5 (1), 303-346.

Yaari, Menachem, "Uncertain Lifetime, Life Insurance, and the Theory of the Consumer," Review of Economic Studies, 1965, 32, 137-150. 


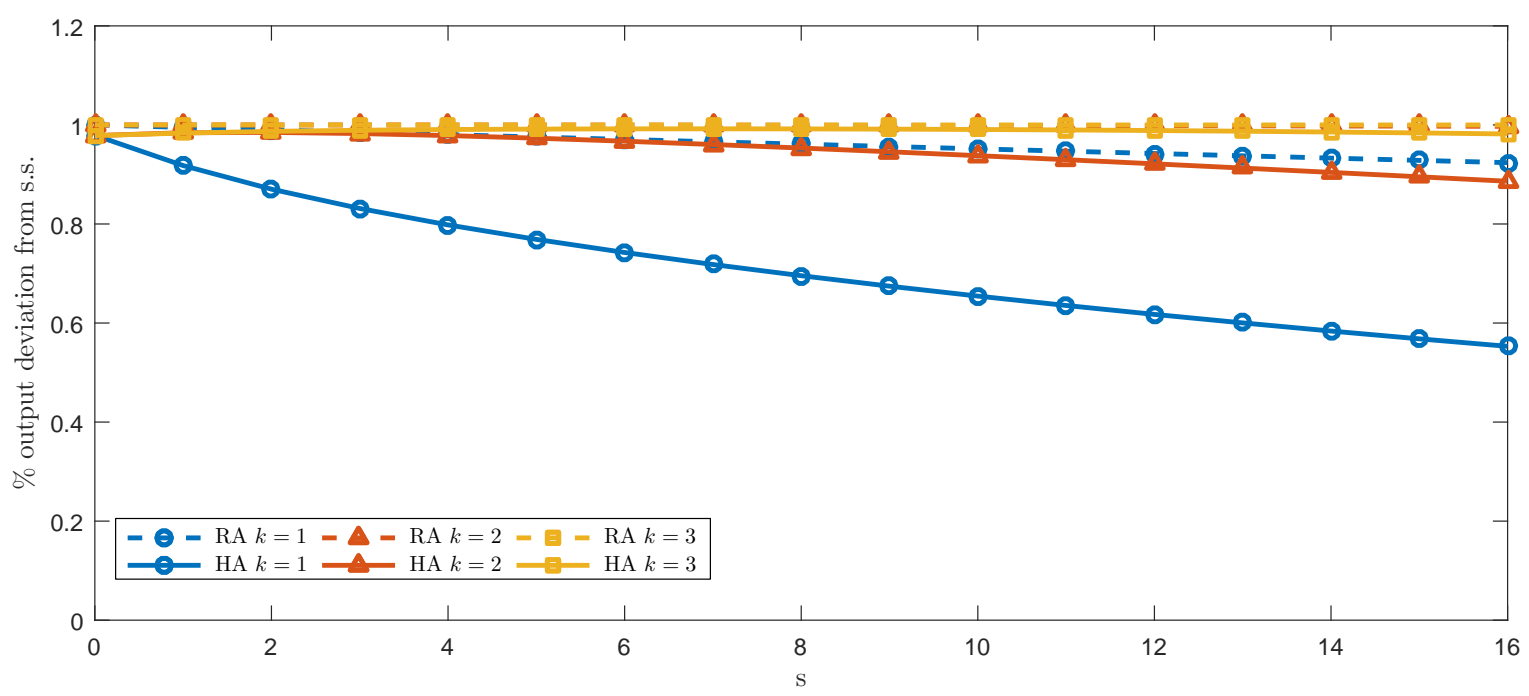

Figure 1: Proportional output response $\epsilon_{0, \tau}^{k}$ at date 0 to a $1 \%$ interest rate cut at different horizons $\tau$ for the baseline incomplete-markets economy (dashed lines) and the completemarkets or representative-agent economy (solid lines). Different colors represent equilibrium output under level- $k$ thinking with different values of $k$.
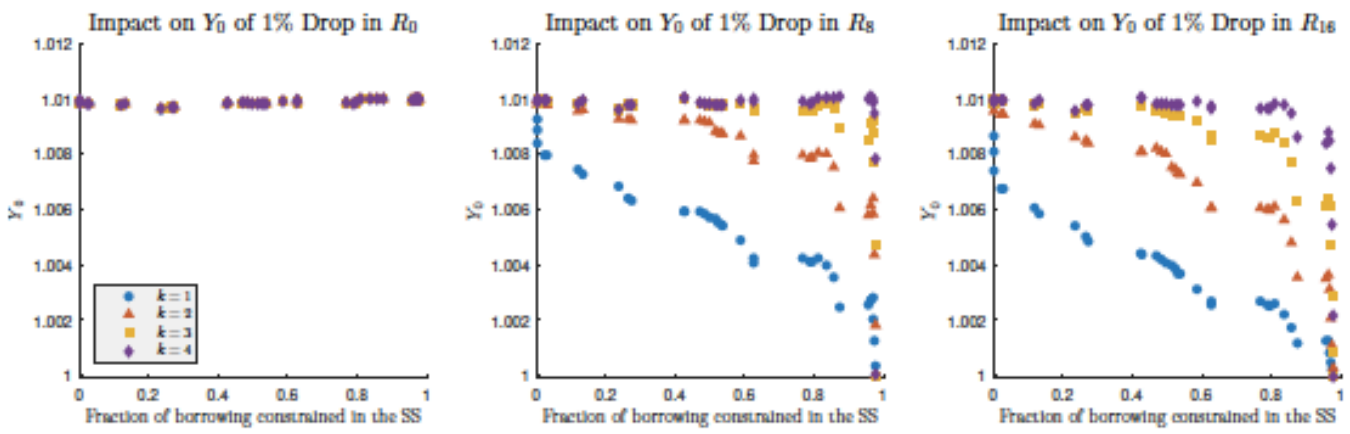

Figure 2: Proportional output response $\epsilon_{0, \tau}^{k}$ at date 0 to a $1 \%$ interest rate cut at a horizon of $\tau=0, \tau=8$ quarters, and $\tau=16$ quarters. Different colors represent equilibrium output under level- $k$ thinking with different values of $k$. Different dots of the same color correspond to economies with different fractions of borrowing-constrained agents in steady state. This variation is achieved by varying the discount factor $\beta$ and amount of liquidity $\delta$ and keeping the steady-state annual interest rate constant at $2 \%$. 

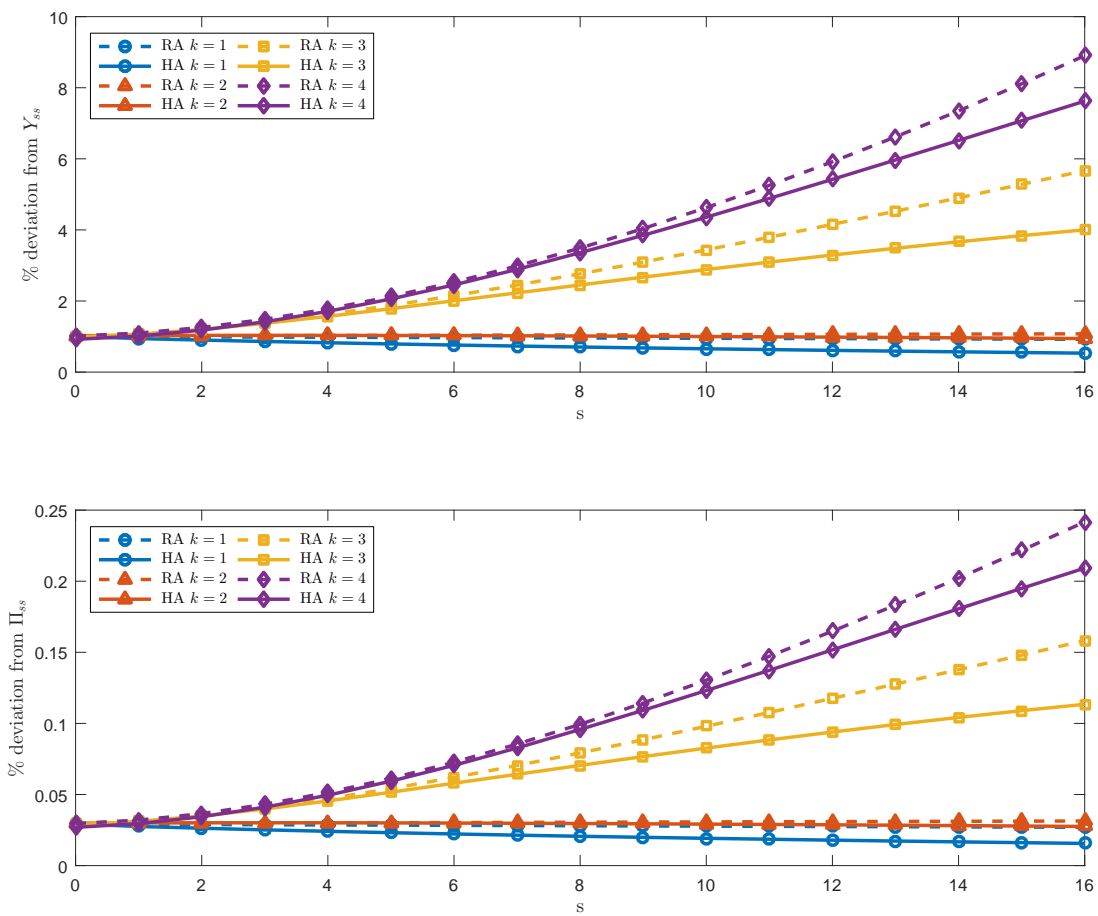

Figure 3: Proportional output response $\epsilon_{0, \tau}^{k}$ and inflation response $\epsilon_{0, \tau}^{\Pi, k}$ at date 0 to a $1 \%$ interest rate cut at different horizons $\tau$ for the baseline incomplete-markets economy (dashed lines) and the complete-markets or representative-agent economy (solid lines). Different colors represent equilibrium output under level- $k$ thinking with different values of $k$.
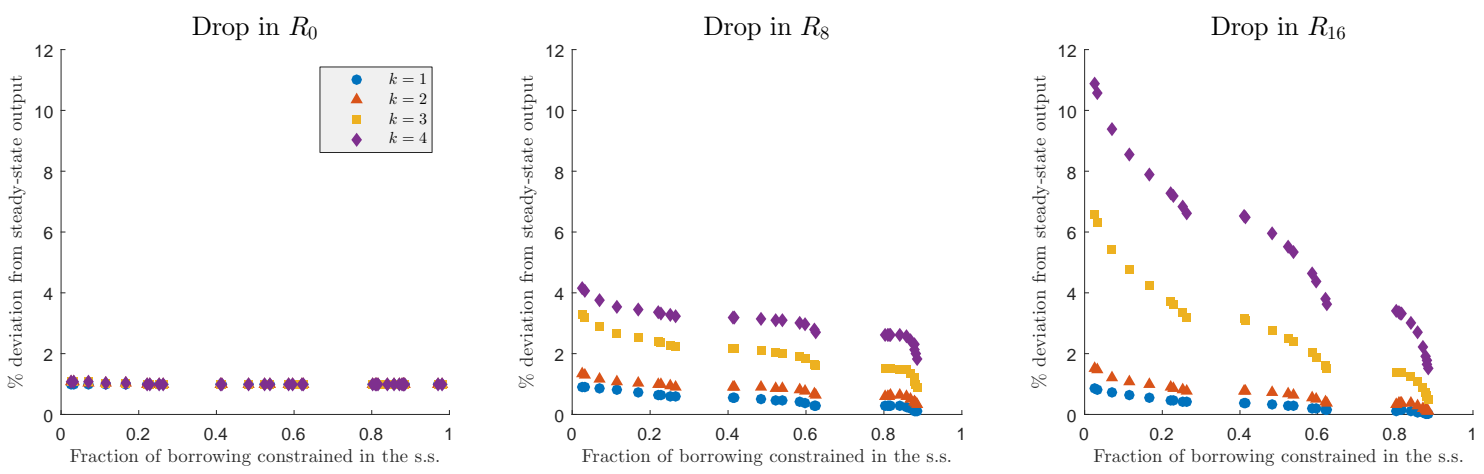

Figure 4: Proportional output response $\epsilon_{0, \tau}^{k}$ at date 0 to a $1 \%$ interest rate cut at a horizon of $\tau=0, \tau=8$ quarters, and $\tau=16$ quarters. Different colors represent equilibrium output under level- $k$ thinking with different values of $k$. Different dots of the same color correspond to economies with different fractions of borrowing-constrained agents in steady state. This variation is achieved by varying the discount factor $\beta$ and amount of liquidity $\delta$ and keeping the steady-state annual interest rate constant at $2 \%$. 


\section{Appendix}

\subsection{Proofs of Propositions 1 and 2}

We consider an initial REE $\left\{R_{t}, Y_{t}\right\}$ which is a steady state with $R_{t}=R$ and $Y_{t}=Y$ for all $t \geq 0$. This only requires that $\beta R=1$. We consider a change $\left\{\hat{R}_{t}\right\}$ in the path for the interest rate $\Delta R_{\tau}$ at date $\tau$ so that $\hat{R}_{\tau}=R+\Delta R_{\tau}$ and $\hat{R}_{t}=R_{t}$ for $t \neq \tau$.

We start by computing the new new REE $\left\{\hat{R}_{t}, \hat{Y}_{t}\right\}$. Because the aggregate model is purely forward looking, we can immediately conclude that for $t>\tau, \hat{Y}_{t}=Y$ and so $\Delta \hat{Y}_{t}=0$. And we guess and verify that for $t \leq \tau, \hat{Y}_{t}=Y\left(1+\frac{\Delta R}{R}\right)^{-\sigma}$ and so

$$
\Delta \hat{Y}_{t}=Y\left[\left(1+\frac{\Delta R}{R}\right)^{-\sigma}-1\right]
$$

This immediately implies that for $t>\tau$, we have $\epsilon_{t, \tau}=0$ and for $t \leq \tau$, we have

$$
\epsilon_{t, \tau}=\sigma
$$

We can perform the decomposition into a partial equilibrium effect and a general equilibrium effect. For $t>\tau$, we have $\Delta \hat{Y}_{t}^{P E}=\Delta \hat{Y}_{t}^{G E}=0$, and for $t \leq \tau$, we have

$$
\begin{aligned}
& \Delta \hat{Y}_{t}^{P E}=Y \frac{\frac{\left(1+\frac{\Delta R}{R}\right)^{-1}-\left(1+\frac{\Delta R}{R}\right)^{\sigma-1}}{R^{\tau-t+1}}}{1+\frac{\left(1+\frac{\Delta R}{R}\right)^{\sigma-1}-1}{R^{\tau-t+1}}}, \\
& \Delta \hat{Y}_{t}^{G E}=Y\left[\left(1+\frac{\Delta R}{R}\right)^{-\sigma}-1\right]-Y \frac{\frac{\left(1+\frac{\Delta R}{R}\right)^{-1}-\left(1+\frac{\Delta R}{R}\right)^{\sigma-1}}{R^{\tau-t+1}}}{1+\frac{\left(1+\frac{\Delta R}{R}\right)^{\sigma-1}-1}{R^{\tau-t+1}}} .
\end{aligned}
$$

This immediately implies that for $t>\tau$, we have $\epsilon_{t, \tau}^{P E}=\epsilon_{t, \tau}^{G E}=0$, and for $t \leq \tau$, we have

$$
\begin{aligned}
\epsilon_{t, \tau}^{P E} & =\sigma \frac{1}{R^{\tau-t+1}} \\
\epsilon_{t, \tau}^{G E} & =\sigma\left(1-\frac{1}{R^{\tau-t+1}}\right) .
\end{aligned}
$$

Next we compute the level- $k$ equilibria $\left\{\hat{R}_{t}, \hat{Y}_{t}^{k}\right\}$. We have

$$
\hat{Y}_{t}^{k}=\frac{\sum_{s=0}^{\tau-t-1} \frac{\hat{Y}_{t+1+s}^{k-1}}{R^{1+s}}+\left(1+\frac{\Delta R}{R}\right)^{-1} \sum_{s=\tau-t}^{\infty} \frac{\hat{Y}_{t+1+s}^{k-1}}{R^{1+s}}}{\frac{1}{R} \frac{1-\frac{1}{R^{\tau-t}}}{1-\frac{1}{R}}+\left(1+\frac{\Delta R}{R}\right)^{\sigma-1} \frac{\frac{1}{R^{\tau-t+1}}}{1-\frac{1}{R}}} .
$$


This implies that

$$
\Delta \hat{\Upsilon}_{t}^{k}=\frac{\sum_{s=0}^{\tau-t-1} \frac{\Delta \hat{Y}_{t+1+s}^{k-1}}{R^{1+s}}+\left(1+\frac{\Delta R}{R}\right)^{-1} \sum_{s=\tau-t}^{\infty} \frac{\Delta \hat{Y}_{t+1+s}^{k-1}}{R^{1+s}}+Y \frac{\left(1+\frac{\Delta R}{R}\right)^{-1}-\left(1+\frac{\Delta R}{R}\right)^{\sigma-1}}{1-\frac{1}{R}} \frac{1}{R^{\tau-t+1}}}{\frac{1}{R} \frac{1-\frac{1}{R^{\tau-t}}}{1-\frac{1}{R}}+\frac{\left(1+\frac{\Delta R}{R}\right)^{\sigma-1}}{1-\frac{1}{R}} \frac{1}{R^{\tau-t+1}}},
$$

from which we get that $\epsilon_{t, \tau}^{k}$ solves the following recursion over $k \geq 0$ :

$$
\epsilon_{t, \tau}^{k}=R\left(1-\frac{1}{R}\right) \sum_{s=0}^{\infty} \frac{\epsilon_{t+1+s, \tau}^{k-1}}{R^{1+s}}+\sigma \frac{1}{R^{\tau-t}},
$$

with the initialization $\epsilon_{t, \tau}^{0}=0$. For $t>\tau$, we have $\epsilon_{t, \tau}^{k}=0$. For $t \leq \tau$ we get

$$
\begin{gathered}
\epsilon_{t, \tau}^{1}=\sigma \frac{1}{R^{\tau-t}}, \\
\epsilon_{t, \tau}^{2}=\sigma \frac{1}{R^{\tau-t}}[1+(R-1)(\tau-t)], \\
\epsilon_{t, \tau}^{3}=\sigma \frac{1}{R^{\tau-t}}\left[1+(R-1)(\tau-t)+(R-1)^{2} \frac{(\tau-t-1)(\tau-t)}{2}\right],
\end{gathered}
$$

and more generally

$$
\epsilon_{t, \tau}^{k}=\sigma \frac{1}{R^{\tau-t}}\left[\sum_{n=0}^{k}(R-1)^{n} \sum_{s_{0}=0}^{\tau-t-1} \sum_{s_{1}=0}^{\tau-t-1-s_{0}} \cdots \sum_{s_{n-2}=0}^{\tau-t-1-s_{n-3}} 1\right] .
$$

\subsection{The Perpetual Youth Model of Borrowing Constraints with $\sigma \neq 1$}

Individual consumption function. When $\sigma \neq 1$, the individual consumption function is given by

$$
c^{*}\left(a_{t}^{i} ;\left\{r_{t+s}\right\},\left\{Y_{t+s}^{e}\right\}\right)=\frac{a_{t}^{i}+\int_{0}^{\infty}(1-\delta) Y_{t+s}^{e} e^{-\int_{0}^{s}\left(r_{t+u}+\lambda\right) d u} d s}{\int_{0}^{\infty} e^{-\int_{0}^{s}\left[(1-\sigma)\left(r_{t+u}+\lambda\right)+\sigma(\rho+\lambda)\right] d u} d s} .
$$

Aggregate state variable. Exactly as in the case $\sigma=1$ treated in Section 4 , the aggregate state variable $\Psi_{t}$ (the wealth distribution) is not required to characterize the aggregate equilibrium since the reduced-form aggregate consumption function is independent of $\Psi_{t}$. 
Reduced-form aggregate consumption function. The reduced-form aggregate consumption function is given by

$$
C\left(\left\{r_{t+s}\right\},\left\{Y_{t+s}^{e}\right\}\right)=\frac{\int_{0}^{\infty} \delta Y_{t+s}^{e} e^{-\int_{0}^{s} r_{t+u} d u} d s+\int_{0}^{\infty}(1-\delta) Y_{t+s}^{e} e^{-\int_{0}^{s}\left(r_{t+u}+\lambda\right) d u} d s}{\int_{0}^{\infty} e^{-\int_{0}^{s}\left[(1-\sigma)\left(r_{t+u}+\lambda\right)+\sigma(\rho+\lambda)\right] d u} d s} .
$$

Equilibrium characterization. For concreteness, we briefly characterize the various equilibria in the context of this particular model. Given beliefs $\left\{Y_{t}^{e}\right\}$, and given the path for interest rates $\left\{r_{t}\right\},\left\{r_{t}, Y_{t}\right\}$ is a temporary equilibrium if and only if the path for aggregate income $\left\{Y_{t}\right\}$ is given by

$$
Y_{t}=\frac{\int_{0}^{\infty} \delta Y_{t+s}^{e} e^{-\int_{0}^{s} r_{t+u} d u} d s+\int_{0}^{\infty}(1-\delta) Y_{t+s}^{e} e^{-\int_{0}^{s}\left(r_{t+u}+\lambda\right) d u} d s}{\int_{0}^{\infty} e^{-\int_{0}^{s}\left[(1-\sigma)\left(r_{t+u}+\lambda\right)+\sigma(\rho+\lambda)\right] d u} d s} \quad \forall t \geq 0 .
$$

Similarly, given the path for interest rates $\left\{r_{t}\right\},\left\{r_{t}, Y_{t}\right\}$ is an REE if and only if the path for aggregate income $\left\{Y_{t}\right\}$ satisfies the fixed point

$$
Y_{t}=\frac{\int_{0}^{\infty} \delta Y_{t+s} e^{-\int_{0}^{s} r_{t+u} d u} d s+\int_{0}^{\infty}(1-\delta) Y_{t+s} e^{-\int_{0}^{s}\left(r_{t+u}+\lambda\right) d u} d s}{\int_{0}^{\infty} e^{-\int_{0}^{s}\left[(1-\sigma)\left(r_{t+u}+\lambda\right)+\sigma(\rho+\lambda)\right] d u} d s} \quad \forall t \geq 0 .
$$

Finally given an initial REE $\left\{r_{t}, Y_{t}\right\}$ and a new interest rate path $\left\{\hat{r}_{t}\right\}$, the level- $k$ equilibria $\left\{\hat{r}_{t}, \hat{Y}_{t}^{k}\right\}$ satisfy the following recursion over $k \geq 0$ :

$$
\hat{Y}_{t}^{k}=\frac{\int_{0}^{\infty} \delta \hat{Y}_{t+s}^{k-1} e^{-\int_{0}^{s} r_{t+u} d u} d s+\int_{0}^{\infty}(1-\delta) \hat{Y}_{t+s}^{k-1} e^{-\int_{0}^{s}\left(r_{t+u}+\lambda\right) d u} d s}{\int_{0}^{\infty} e^{-\int_{0}^{s}\left[(1-\sigma)\left(r_{t+u}+\lambda\right)+\sigma(\rho+\lambda)\right] d u} d s} \quad \forall t \geq 0 .
$$

with the initialization that $\hat{Y}_{t}^{0}=Y_{t}$ for all $t \geq 0$.

We now turn to the computation of the different interest rate elasticities of output around a steady state $\operatorname{REE}\left\{R_{t}, Y_{t}\right\} Y_{t}=Y>0$ and $r_{t}=r$ for all $t \geq 0$, where the steady-state interest rate $r$ is given by

$$
1=[(1-\sigma)(r+\lambda)+\sigma(\rho+\lambda)]\left[\frac{\delta}{r}+\frac{1-\delta}{r+\lambda}\right],
$$

so that $r=\rho$ in the limit where the frequency of binding borrowing constraints $\lambda$ goes to 0 .

Monetary policy at different horizons under RE. The interest rate elasticities of output $\epsilon_{t, \tau}$ are 0 for $t>\tau$ and otherwise depend only on the horizon $\tau-t$. For $t \leq \tau$, they are 
the solution of the following integral equation

$$
\begin{aligned}
\epsilon_{t, \tau}=[(1-\sigma)(r+\lambda)+\sigma(\rho+\lambda)]\left[\delta \int_{0}^{\tau-t} \epsilon_{t+s, \tau} e^{-r s} d s\right. & \left.+(1-\delta) \int_{0}^{\tau-t} \epsilon_{t+s, \tau} e^{-(r+\lambda) s} d s\right] \\
+[(1-\sigma)(r+\lambda)+\sigma(\rho+\lambda)]\left[\delta \frac{e^{-r(\tau-t)}}{r}\right. & \left.+(1-\delta) \frac{e^{-(r+\lambda)(\tau-t)}}{r+\lambda}\right] \\
& +(\sigma-1) e^{-[(1-\sigma)(r+\lambda)+\sigma(\rho+\lambda)](\tau-t)} .
\end{aligned}
$$

Define

$$
A_{s}=[(1-\sigma)(r+\lambda)+\sigma(\rho+\lambda)]\left[\delta e^{-r s}+(1-\delta) e^{-(r+\lambda) s}\right]
$$

and

$B_{\tau}=[(1-\sigma)(r+\lambda)+\sigma(\rho+\lambda)]\left[\delta \frac{e^{-r \tau}}{r}+(1-\delta) \frac{e^{-(r+\lambda) \tau}}{r+\lambda}\right]+(\sigma-1) e^{-[(1-\sigma)(r+\lambda)+\sigma(\rho+\lambda)] \tau}$.

Then the solution is

$$
\epsilon_{t, \tau}=\sum_{n=1}^{\infty} \int_{0}^{\tau-t} A_{\tau-t-s_{1}} \int_{0}^{s_{1}} A_{s_{1}-s_{2}} \cdots \int_{0}^{s_{n-1}} A_{s_{n-1}-s_{n}} B_{s_{n}} d s_{1} d s_{2} \ldots d s_{n}
$$

with the convention that $s_{0}=\tau-t$. The PE and GE effects are zero for $t>\tau$ and otherwise only depend on the horizon $\tau-t$ and are given by

$$
\begin{gathered}
\epsilon_{t, \tau}^{P E}=B_{\tau-t} \\
\epsilon_{t, \tau}^{G E}=[(1-\sigma)(r+\lambda)+\sigma(\rho+\lambda)]\left[\delta \int_{0}^{\tau-t} \epsilon_{t+s, \tau} e^{-r s} d s+(1-\delta) \int_{0}^{\tau-t} \epsilon_{t+s, \tau} e^{-(r+\lambda) s} d s\right]
\end{gathered}
$$

with $\epsilon_{t, \tau}=\epsilon_{t, \tau}^{P E}+\epsilon_{t, \tau}^{G E}$.

These expressions can be simplified in three special cases. The first case is when $\sigma=1$ and is treated in the main body of the paper.

The second case is when the frequency of binding borrowing constraints $\lambda$ goes to 0 , where we get

$$
r=\rho,
$$

and for for $t \geq \tau$,

$$
\epsilon_{t, \tau}=\sigma, \quad \epsilon_{t, \tau}^{P E}=\sigma e^{-r(\tau-t)}, \quad \epsilon_{t, \tau}^{G E}=\sigma\left[1-e^{-r(\tau-t)}\right]
$$


The third case is when there is no outside liquidity $\delta=0$, where we get

$$
\begin{gathered}
r=\rho, \\
A_{s}=(r+\lambda) e^{-(r+\lambda) s,} \\
B_{\tau}=\sigma e^{-(r+\lambda) \tau},
\end{gathered}
$$

and for $t \geq \tau$,

$$
\epsilon_{t, \tau}=\sigma, \quad \epsilon_{t, \tau}^{P E}=\sigma e^{-(r+\lambda)(\tau-t)}, \quad \epsilon_{t, \tau}^{G E}=\sigma\left[1-e^{-(r+\lambda)(\tau-t)}\right] .
$$

